\title{
The Transversal Stiffness of Skeletal Muscle Fibers and Cardiomyocytes in Control and After Simulated Microgravity
}

\author{
Irina V. Ogneva and Igor B. Ushakov \\ State Scientific Center of Russian Federation Institute of Biomedical Problems \\ Russian Academy of Sciences \\ Russia
}

\section{Introduction}

The relevance of a problem of studying of mechanical characteristics of muscle fibers is stipulated by the huge number of diseases such as myopathies and myodystrophies leading to the significant change in activity of muscle cells. Moreover, the decreasing in functional properties of a muscle system is one of the main medical problems preventing the longlasting space mission. The same reason complicates the course and prolongs the terms of readaptation period in some neurological and traumatological diseases.

Generally, the muscle fiber is a 3D mechanical structure in which the force transmission is performed both in longitudinal and transverse directions (Bloch \& Gonzalez-Serratos, 2003). The structural features of a muscle fiber provide the efficacy of such transmission, whether the muscle fiber is a cell structure extended longitudinally with contractile apparatus formed by myofibrils and occupying the most part of cell volume. In general, the mechanical characteristics of a muscle fiber are determined by structural and functional interaction of three compartments with principally different mechanical properties: myofibrillar apparatus, extra-sarcomeric cytoskeleton (costameres) and sarcolemma with cortical cytoskeleton.

The flexible, or viscoelastic properties are generally implicated under the mechanical characteristics of one or another biological structure. In relation to a muscle fiber, the stiffness (that is analogue to the spring stiffness, in N/m) and the Young's modulus (in Pa) in both longitudinal (with deformation along the predominated axis) and transversal directions (with deformation in direction perpendicular to the main direction axis) are determined most often. Obviously, such two parameters are interconnected and are the integral parts of fiber stiffness. When measuring the longitudinal stiffness by compression-tension, the transversal structures contributes to the damping of deformation due to their own elastic properties. Similarly, in case of significant deformation in transversal direction, the contribution of the stiffness of the myofibrillar apparatus is present in the transversal stiffness value.

Atomic force microscopy (AFM) is one of the most informative methods used to obtain the information on transversal stiffness of both the myofibrillar apparatus and sarcolemma 
together with related costameres. The determination of characteristics is usually performed in contact mode in liquid measuring the force curves, and then using of solution of the Hertz contact problem, the Young's modulus and transverse rigidity is calculated. The fluctuation of indentation depth when evaluating the force curves allows estimation the stiffness of a complete fiber and sarcolemma as well.

\subsection{Calculation of transversal stiffness and Young's modulus of a sample by force curves}

Calculating the stiffness parameters of a sample using the data from atomic force microscopy is a dimensional contact problem. The contact stiffness to be calculated is the ratio of force to vertical movement. When the cantilever tip is conical, vertical movement can be determined quite easily, and the force can be calculated using the cantilever's deflection. Solving such contact problem that has many possible modifications (such as Sneddon's modification (Sneddon, 1965), Hertz contact problem (Hertz, 1882)) enables calculating the Young's modulus of the material. It should be noted that the section of the cantilever tip in most cases is not strictly conical, but rather a little rounded at the end. This is why determining the contact area of the cantilever and the sample is a key issue.

There are a number of works investigating these issues, but one of the first publications concerning mechanical properties of muscle fibers (Mathur et al., 2001) list formulas to determine the Young's modulus for different types of cantilevers that are quite correct from the mechanical point of view:

$$
\mathrm{E}=\frac{1-\mathrm{v}^{2}}{\pi} \cdot \frac{\mathrm{kd}}{\varphi(\delta)}
$$

where $\mathrm{k}$ is cantilever stiffness, $\mathrm{d}$ is cantilever deflection, $\mathrm{v}$ is Poisson's ratio, $\varphi(\delta)$ is the function characterizing the dependency of the cantilever indentation $\delta$ on its geometrical parameters.

The stiffness of cantilever $\mathrm{k}$ when the probes supplied by the manufacturer have a range of stiffness values can be determined either by calibrating using a cantilever with a known stiffness by reading the force curves on a known stiff surface (e.g. glass), or calculated theoretically by measuring the resonance frequency of cantilever oscillations. Poisson's ratio $\mathrm{v}$ for each material is determined experimentally. In most cases, it equals 0.5 for cells. Thus, Mathur et al. (2001), believed that loss of liquid in the examined muscle fibers and endothelium cells is insignificant, and, along with a number of other researchers (Radmacher et al., 1996; Shin \& Athanasiou, 1999; Weisenhorn et al., 1993), assumed that the cell is not compressible and used $v=0.5$. Collinsworth et al. (2002) used the same value to determine the stiffness $\mathrm{C} 2 \mathrm{C} 12$ of myoblasts in mice.

For a cantilever whose tip is conical with an axis parallel to axis $z$, the function $\varphi(\delta)$ may be determined as (Mathur et al., 2001):

$$
\varphi(\delta)=\delta^{2}\left[\frac{2 \operatorname{tg}(\mathrm{a})}{\pi^{2}}\right],
$$


where $\delta$ is the indentation depth, a is half of the cone angle of the cantilever tip. The stiffness modulus is then as follows:

$$
\mathrm{E}=\frac{\pi\left(1-\mathrm{v}^{2}\right)}{2 \operatorname{tg} \alpha} \cdot \frac{\mathrm{kd}}{\delta^{2}}
$$

For a rounded cantilever, the function $\varphi(\delta)$ is as follows (Mathur et al., 2001):

$$
\varphi(\delta)=\frac{2}{\pi}\left[\operatorname{a\delta }-\frac{a^{2}}{2 \operatorname{tg} \alpha}\left(\frac{\pi}{2}-\arcsin \left(\frac{b}{a}\right)\right)-\frac{a^{3}}{3 R}+\sqrt{a^{2}-b^{2}}\left(\frac{b}{2 \operatorname{tg} \alpha}+\frac{a^{2}-b^{2}}{3 R}\right)\right],
$$

where $\mathrm{R}$ is the rounding radius of the cantilever tip, $\mathrm{b}=\mathrm{R} \cos \alpha$, $\mathrm{a}$ is the contact radius determined from the following equation:

$$
\delta+\frac{a}{R}\left(\sqrt{a^{2}-b^{2}}-a\right)-\frac{a}{\operatorname{tg} \alpha}\left(\frac{\pi}{2}-\arcsin \left(\frac{b}{a}\right)\right)=0 .
$$

It should be noted that the last formula or modifications thereof are most often used for calculations, assuming that the vertical section of the cantilever tip is conical. For instance, Defranchi et al. (2005) used the following formula in their research:

$$
\mathrm{E}=\frac{\sqrt{\pi}\left(1-\mathrm{v}^{2}\right)}{2} \cdot \frac{\mathrm{S}}{\sqrt{\mathrm{A}}}
$$

where $\mathrm{S}$ is the transversal stiffness of the sample determined as the slope of the force curve, $\mathrm{A}$ is the contact area.

\subsection{The transversal stiffness of intact muscle fibers and sarcolemma}

Mathur et al. (2001) obtained some of the first data about the mechanical properties of intact muscle fibers of the skeletal and cardiac muscle compared to endothelium cells using the AFM in liquid. The main working hypothesis of the research was that the stiffness model and viscosity of these three cell types will be different due to various structures and functional roles. Experiments were conducted using the fibers of a rabbit's cardiac muscle, $\mathrm{C} 2 \mathrm{C} 12$ of the myoblast of adult $\mathrm{C} 3 \mathrm{H}$ mice, and cells of the endothelium of HUVEC (Human Umbilical Venous Cord Endothelial Cell). The authors demonstrated that the stiffness modulus of endothelial cells was $\mathrm{E}=6.8 \pm 0.4 \mathrm{kPa}$ near the core, $\mathrm{E}=3.3 \pm 0.2 \mathrm{kPa}$ on the cell body and $\mathrm{E}=1.4 \pm 0.1$ $\mathrm{kPa}$ near the end of the cell. Unlike the endothelium, the cardiac and skeletal muscles did not demonstrate any systematic changes of the stiffness modulus depending on the place of the contact point between the cantilever and the surface. For cardiac muscle cells, the Young's modulus was $E=100.3 \pm 10.7 \mathrm{kPa}$, while for skeletal muscle cells it was $E=24.7 \pm 3.5 \mathrm{kPa}$. Thus, the most rigid and, consequently, the most resisting to deformation are fibers of the cardiac muscle, which, in the opinion of the authors, is due to its constant rhythmical activity.

Defranchi et al. (2005) conducted experiments to study the structure and transversal stiffness of sarcolemma of fully differentiated muscle fibers under various conditions. The 
experiments were conducted with muscle fibers of skeletal muscles of CD1 mice, both in the culture and dried in the air. In order to obtain information about the sarcolemma structure, the authors used the semi-contact mode which enabled obtaining more informative images due to the lack of damage of sarcolemma by the cantilever. The authors demonstrated that AFM images show the convexity of sarcolemma (similar convexity was shown in our experiments with the soleus muscle of rat - see Fig. 2) and suggested that they are due to the presence of costamer near the Z-disk. In order to prove that, one of the costamer's proteins, a-actinin-2, was linked with fluorescent spheric antibodies $500 \mathrm{~nm}$ in diameter, which permits discovering them with the AFM. By comparing the optical and structural images, the authors have confirmed their hypothesis. Moreover, they have managed to see open Ttubules stretched along the Z-disks. Mechanical properties were measured in the contact mode, and the maximum forced applied to the membrane was $1 \mathrm{nN}$, while the indentation depth was between several hundred up to $1000 \mathrm{~nm}$. The values of the stiffness modulus listed in the paper was $\mathrm{E}=61 \pm 5 \mathrm{kPa}$.

The data of the Defranchi et al. (2005) indicated the stiffness modulus exceed by almost 2.5 times the results of Mathur et al. (2001). This may be due to Defranchi et al. using fully differentiated cells in their research, while Mathur et al. used myoblasts. Moreover, Lieber et al. (2004) showed that old rats (30 months) had the Young's modulus of cardiac myocytes of $42.5 \pm 1.0 \mathrm{kPa}$, while younger rats (4 months) it was reliably lower, at $35.1 \pm 0.7 \mathrm{kPa}$. Such difference in the mechanical properties of muscle fibers and cardiac myocytes at different stages of development may denote that the ontogenetic development of the expression of proteins forming the structural basis of transversal stiffness is uneven. This issue was studied by Collinsworth et al. (2002). They studied the mechanical properties of muscle cells at various stages, from myocytes up to muscle fibers, and discovered significant increase of the Young's modulus on the 8th day after the differentiation began. Thus, for non-differentiated myoblasts, the stiffness modulus was $E=11.5 \pm 1.3 \mathrm{kPa}$, while on the 8th to 10th day of differentiation it was $\mathrm{E}=45.3 \pm 4.0 \mathrm{kPa}$. The viscosity estimated using the hysteresis formed at the forward and backward movement of the cantilever when reading the force curves did not change during the differentiation. The authors' suggestion that changes in the stiffness modulus and the formation of tubules are related was not confirmed by experiments, because after colchicine treatment, the Young's modulus and the viscosity of muscle cells did not change. However, treatment with cytochalasin D resulted in significant reduction of the stiffness modulus, while the viscosity remained unchanged. For that reason, the authors link changes in the stiffness properties of muscle cells during differentiation with the development of the actin-myosin system. It should be noted that Collinsworth et al. did not analyze the contribution of the extra-sarcomeric cytoskeleton to the transversal stiffness of muscle fibers, although treatment with cytochalasin D could cause destruction of the cortical layer of actin filaments.

\subsection{The transversal stiffness of myofibrillar apparatus}

The contractile apparatus of muscle fiber has mechanical properties that are essentially different from sarcolemma linked with costameres, since it has another structure. E.g. Collinsworth et al. (2002) suggested that the biggest contribution to transversal stiffness is mainly from transversal bridges between actin and myosin filaments. The analysis of mechanical properties of myofibrillar bundles and separate myofibrils under various conditions (active and passive contraction, relaxation) may clarify this issue. 
In order to obtain demembranized fibers, strong detergents like Triton-X100 are used, which destroy not only the sarcolemma but the sarcoplasmatic reticulum as well. Some myofibrils are obtained from demembranized fibers by way of homogenization.

Nyland \& Maughan (2000) studied bundles of myofibrils of the flight musle of Drosophila, using rigor solution (without ATP), activating solution (pCa 4.5) and relaxing solution (pCa 8.0). The selected method of studying the mechanical properties was AFM in contact mode with indentation depth of $10 \mathrm{~nm}$. The authors have obtained the following results: in rigor solution: transversal stiffness $10.3 \pm 5.0 \mathrm{pN} / \mathrm{nm}$, Young's modulus $94 \pm 41 \mathrm{kPa}$; in the activating solution: transversal stiffness $5.9 \pm 3.1 \mathrm{pN} / \mathrm{nm}$, Young's modulus $55 \pm 29 \mathrm{kPa}$; in the relaxing solution: transversal stiffness $4.4 \pm 2.0 \mathrm{pN} / \mathrm{nm}$, Young's modulus: $40 \pm 17 \mathrm{kPa}$. The authors link such difference in stiffness to the transversal "flexibility" of the myosin molecule, assuming that myosin heads may be at a different angle to the actin thread which, consequently, leads to different transversal stiffness. It should be noted, however, that authors do not provide any information about the validity of differences between the obtained values of transversal stiffness and Young's modulus under different conditions.

Zhu et al. (2009) analyzed bundles of myofibrils from the left ventricle of cows. The authors have demonstrated that the transversal stiffness near the Z-disk in the relaxed state is $18 \pm 2.5$ $\mathrm{pN} / \mathrm{nm}$ (Young's modulus: $115 \pm 12 \mathrm{kPa}$ ); in the area of crossing of actin and myosin filaments: $6 \pm 1 \mathrm{pN} / \mathrm{nm}(52 \pm 8 \mathrm{kPa})$; in the area of M-band: $11 \pm 0.5 \mathrm{pN} / \mathrm{nm}(90 \pm 11 \mathrm{kPa})$. The values in the same areas in rigor state were as follows: for Z-disk: $25 \pm 2 \mathrm{pN} / \mathrm{nm}(98 \pm 10)$; in the area of crossing of actin and myosin filaments: $10 \pm 1 \mathrm{pN} / \mathrm{nm}(42 \pm 4 \mathrm{kPa})$; in the area of the M-band: $17 \pm 0.5 \mathrm{pN} / \mathrm{nm}(65 \pm 7 \mathrm{kPa})$.

Unlike Nyland \& Maughan (2000) and Zhu et al. (2009), Akiyama et al. (2006) studied the structure and transversal stiffness of individual myofibrils rather than bundles cut out of muscle fibers of the cardiac and skeletal muscles of young rabbits and newborn rats. The method of study of the transversal stiffness was the same, with the difference that the indentation depth was $25-30 \mathrm{~nm}$. Studies of the structure of individual myofibrils showed that they are approximately $1 \mu \mathrm{m}$ in diameter, and the sarcomere length is about $2 \mu \mathrm{m}$. The transversal stiffness was studied in the relaxing and rigor solutions; the change of stiffness was monitored after myofibrils were treated with calpain and tripsin. The Z-line of myofibrils of skeletal muscles in the rigor solution was $100 \mathrm{~nm}$ wide and had the stiffness value of $7.7 \mathrm{pN} / \mathrm{nm}$, while the same values for the cardiac muscle were $320 \mathrm{~nm}$ and $25.8 \mathrm{pN} / \mathrm{nm}$. The stiffness of the myofibril of the cardiac muscle in rigor solution around the M-band which was about $200 \mathrm{~nm}$ wide was $11 \mathrm{pN} / \mathrm{nm}$. The paper does not provide any data about the stiffness of myofibrils of skeletal muscles near the M-band, because it could not be identified using the AFM image of the surface. In the relaxing solution, the stiffness of myofibrils of skeletal muscles was quite homogeneous and was 3 $\mathrm{pN} / \mathrm{nm}$ on average, versus the myofibrils of the cardiac muscle, where the stiffness varied between 4 and $11 \mathrm{pN} / \mathrm{nm}$. Using the Hertz model, the authors have calculated the Young's modulus for individual myofibrils that was $61 \mathrm{kPa}$ for skeletal muscles and 145 $\mathrm{kPa}$ for the cardiac muscle; in the relaxing stage, it was $5 \mathrm{kPa}$ for myofibrils of skeletal muscles and $61 \mathrm{kPa}$ for the cardiac muscle. In order to identify the mechanisms causing such values of transversal stiffness, the authors have treated myofibrils in the rigor stage first with calpain and then with tripsin. with calpain, the transversal stiffness of the 
myofibrils of the cardiac muscle near the Z-line quickly (2 or 3 minutes) fell from 21 $\mathrm{pN} / \mathrm{nm}$ to $11 \mathrm{pN} / \mathrm{nm}$, or to $2 \mathrm{pN} / \mathrm{nm}$ for the skeletal muscle, and did not change over time. Several minutes after the tripsin treatment began, the transversal stiffness of the Zline of myofibrils of the skeletal muscle was $3 \mathrm{pN} / \mathrm{nm}$ and $12 \mathrm{pN} / \mathrm{nm}$ for the cardiac muscle, but it then continued to decrease to $5 \mathrm{pN} / \mathrm{nm}$. The authors link this kind of change in transversal stiffness to calpain quickly destroying two main structural proteins of the Z-disk, a-actinin-2 and titin, and it occurs much faster for skeletal myofibrils than for cardiac myofibrils. Unlike calpain, tripsin first hydrolyzes titin, while a-actinin-2 is subject to a much slower degradation.

\subsection{Muscle fibers under simulated microgravity}

According to the few existing sources regarding the reaction of skeletal muscle cells to gravitational unloading, one of the first events is the accumulation of calcium ions demonstrated for the soleus muscle as early as after two days of antiorthostatic suspension of rear limbs of mice (Ingalls et al., 1999, 2001). In our paper, we have shown that the accumulated calcium ions in fibers of the soleus muscle rat and Mongolian gerbil peak as early as one day after the gravitational unloading, and for the medial head of the gastrocnemius muscle and tibialis anterior muscle the peak was somewhat later, on the seventh day of antiorthostatic suspension (Ogneva et al., 2009). The increase of the basal level of calcium ions may cause activation of calpains (Enns et al., 2007; Altaeva et al., 2010) and subsequent destruction of muscle fiber. However, the ways of such accumulation remain unknown. It may occur via the L-channels, but mechanically sensitive channels, such as trp-channels, may also have something to do with it. In any case, the operation of channels built into the membrane depends on the condition of sarcolemma itself and the condition of the cytoskeleton linked to it. Moreover, it can be suggested that the mechanical properties of cardiac myocytes will change in a different way compared to fibers of skeletal muscles, since the load on the cardiac muscle under the microgravity conditions increases, while the load on the skeletal muscles of hind limbs decreases.

It is difficult to directly evaluate the native condition of the cytoskeleton of muscle fibers under the membrane. But determining its mechanical properties, namely, the transversal stiffness may help in the analysis of its structural changes.

Moreover, complex sarcomeric structure of muscle fiber suggests that the transversal stiffness of various areas of sarcolemma and the contraction apparatus, namely the Z-disk, M-band and the area between them will be different. The differentiation of the stiffness values is especially interesting in connection with, for example, the signaling functions of various costamere proteins, possibly depending on its structure.

We have not been able to find any data about the scale of changes of the transversal stiffness of fibers of either skeletal or cardiac muscles under the conditions of gravitational unloading. The formation processes of the adaptation pattern of the mechanical properties of muscle fibers under the conditions of gravitational unloading should depend, first of all, on the level of nervous activation. It can be suggested that changes in the nervous activation will lead to changes in the properties of the contraction apparatus itself, which will provide an adequate response to microgravity conditions. 


\section{Materials and methods}

The object of the research was the soleus muscle (Sol), the medial gastrocnemius muscle (MG) and the tibialis anterior muscle (TA) of rat and Mongolian gerbil, as well as the left ventriculum of rat. The rat is often used in research, unlike the gerbils who started to be used more often again due to the continued missions of Russian biosatellites in 2007 after the FOTON-3 mission (September 2007, Russia). In space biology, the Mongolian gerbil (Meriones unguiculatus) is used as an object of experimental research. Gerbils have a longer Henle's loop compared to other mammals, which enables nearly complete reabsorption of water in kidneys (Robinson, 1959). For this reason, gerbils are very convenient to study the effect of parameters of water-salt metabolism on the resistivity of various functions of the organism under the conditions of microgravity.

To simulate the gravitational unloading conditions in rodents, antiorthostatic suspension was used according to the Ilyin-Novikov method as amended by Morey-Holton E. et al. (2005). The duration of gravitational unloading for rat and Mongolian gerbils was 1, 3, 7 and 12/14 days. Each group contained 7 animals. The average body masses in each group of each animal were reliably similar. All procedures with animals were approved by the biomedical ethics committee of the State Scientific Center of Russia Institute of Biomedical Problems of the Russian Academy of Sciences.

\subsection{Sample preparation}

The skeletal muscle was cut from tendon to tendon and, for the purpose of partial destruction of the cell membrane, was treated according to the chemical skinning method described earlier in Stevens et al. (1993). Cardiac myocytes were obtained using the standard method (Zhu et al., 2009), but at first without using Triton X-100. Before the experiments, samples were stored at $-20^{\circ} \mathrm{C}$ in a buffer containing equal percentage (by volume) of relaxing solution $\mathrm{R}$ ( $20 \mathrm{mM}$ MOPS, $170 \mathrm{mM}$ of potassium propionate, $2.5 \mathrm{mM}$ of magnesium acetate, $5 \mathrm{mM}$ of $\mathrm{K}_{2}$ EGTA, $2.5 \mathrm{mM}$ of ATP) and glycerol. On the day of the experiment, the samples were transferred to solution $\mathrm{R}$ where single glycerinated muscle fibers were singled out.

In order to obtain demembranized cells, single glycerinated muscle fibers in the R solution were incubated with the Triton X-100 detergent with the final concentration of $2 \%$ vol. within 12 hours at $+4^{\circ} \mathrm{C}$. Such concentration of the detergent used and the long incubation time enable completely removing the membranes of muscle fibers to analyze only the myofibrillar apparatus. After treatment with the detergent, the obtained demembranized fibers were cleaned in the R solution.

In order to measure the transversal stiffness, the obtained fibers were fixed on the bottom of the liquid cell of the atomic force microscope, attaching their tips with special Fluka shellac wax-free glue (Sigma). Depending on the series of the experiments, the cell was filled either with the relaxing solution $\mathrm{R}$ or activating solution $\mathrm{A}(20 \mathrm{mM}$ of MOPS, $172 \mathrm{mM}$ of potassium propionate, $2.38 \mathrm{mM}$ of magnesium acetate, $5 \mathrm{mM}$ of CaEGTA, $2.5 \mathrm{mM}$ of ATF), or with the rigor solution $\mathrm{Rg}(20 \mathrm{mM}$ of MOPS, $170 \mathrm{mM}$ of potassium propionate, $2.5 \mathrm{mM}$ of magnesium acetate, $5 \mathrm{mM}$ of $\mathrm{K}_{2} \mathrm{EGTA}$ ). All contractions of the fiber were isometric, since the tips of the fibers were fixed. All experiments were conducted at $+16^{\circ} \mathrm{C}$. 


\subsection{Atomic force microscopy}

The method of measurements has been described earlier in details (Ogneva et al., 2010). Measurements of transversal stiffness of both glycerinated and demembranized fibers were conducted using the Solver-P47-ProTM platform (NT-MDT, Russia). The stiffness $(\mathrm{N} / \mathrm{m})$ for each cantilever was adjusted using the resonance position.

Work in the liquid was performed with soft cantilevers with the stiffness coefficient of about $0.05 \mathrm{~N} / \mathrm{m}$. The contact mode was used to obtain the image and to measure the transversal stiffness. Radius $r_{c}$ of the tip of all cantilevers used was assumed to be $10 \mathrm{~nm}$.

AFM images were used to estimate the length of sarcomeres and to identify the Z-disk and the M-band. The length of the sarcomere was understood as the distance between two adjacent convexities that were deemed a Z-disk.

Mechanical properties of muscle fibers were determined by first obtaining a calibration force curve on the glass to calculate the cantilever deflection conversion coefficient to convert it from the units of current into the units of length, a (m/A). Then, the force curves in the points of interest of the fiber were read, obtaining the ratio $\mathrm{y}(\mathrm{x})$, where $\mathrm{y}$ is the measured cantilever deviation (in A), and $x$ is the generalized indentation depth (in $\mathrm{m}$ ). Then, the real indentation depth of the fiber and the force applied to it were identified using the following formulae:

$$
\begin{aligned}
& \mathrm{h}_{\mathrm{s}}=\mathrm{x}-\mathrm{y} \cdot \mathrm{a}, \\
& \mathrm{F}_{\mathrm{s}}=\mathrm{y} \cdot \mathrm{a} \cdot \mathrm{k}_{\mathrm{c}},
\end{aligned}
$$

where $h_{s}$ is the real indentation depth $(m), F_{s}$ is the real force applied to fiber $(N), k_{c}$ is the cantilever stiffness coefficient $(\mathrm{N} / \mathrm{m})$.

Then, at the indentation depth of $150 \mathrm{~nm}$, the change of the applied force was determined and the stiffness of the sample was determined as:

$$
\mathrm{k}_{\mathrm{s}}=\frac{\mathrm{F}_{\mathrm{s}}}{\mathrm{h}_{\mathrm{s}}}
$$

Then, the curve $F_{s}\left(h_{s}\right)$ was drawn and approximated with the following dependency reflecting the solution of the Hertz contact problem for the rounded tip of the cantilever in order to discover the generalized stiffness modulus $b\left(\mathrm{~N} / \mathrm{m}^{3 / 2}\right)$ :

$$
\mathrm{F}_{\mathrm{s}}=\mathrm{bh}_{\mathrm{s}}^{\frac{3}{2}}
$$

The Young's modulus was calculated using the formula:

$$
\mathrm{E}_{\mathrm{s}}=\frac{3 \mathrm{~b}\left(1-\mu_{\mathrm{s}}^{2}\right)}{4 \mathrm{r}_{\mathrm{c}}^{\frac{1}{2}}},
$$

where $\mathrm{E}_{\mathrm{s}}$ is the Young's modulus $(\mathrm{Pa}) ; \mu_{\mathrm{s}}$ is the Poisson's ratio. Assuming that the cell is not compressible, it is usually assumed that the Poisson's ratio is 0.5 (Collinsworth et al., 
2002; Mathur et al., 2001; Radmacher et al., 1996; Shin \& Athanasiou, 1999; Weisenhorn et al., 1993). An example of such processing is provided in Figure 1.

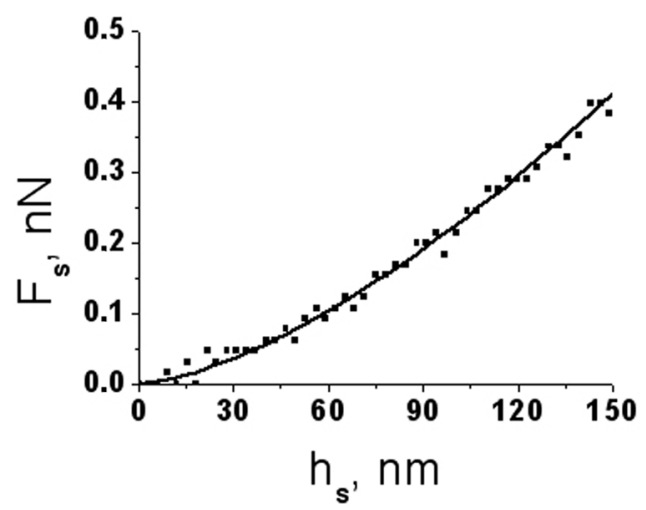

Fig. 1. Sample force-distance curve obtained at Z-disk projection on relaxed permeabilized fiber, showing a typical dependency of the applied force on the depth of indentation. Squares show experimental points, line represents the least-square fit to Eq. 9 (Young's modulus $38.5 \mathrm{kPa}$, apparent transversal stiffness $2.72 \mathrm{pN} / \mathrm{nm}$ at $150 \mathrm{~nm}$ indentation).

The above results were processed in an ad hoc program for MatLab 6.5 (The MathWorks, Natick, MA). The results obtained during the experiment were statistically processed with standard methods implemented in Microsoft Excel and Origin 6.0. The data was represented as $M \pm m$, where $M$ is the average value of the estimated parameter and $m$ is the standard average value error. At least 31 measurements were made to obtain each average value.

\section{Results}

\subsection{Analysis of structure of sarcolemma surface and contractile apparatus of muscle fibers}

The results in the following section 3.1 were described in details earlier (Ogneva, 2010). The analysis of striation of glycerinated muscle fibers in the relaxing solution shows that near the Z-line and the M-band the fiber is thicker compared to the surface of the semisarcomere, however, it is more prominent near the Z-line (Fig. 2). This kind of surface of muscle fiber near the Z-line is due to the sub-membrane structure, the costamere that links the membrane of muscle fiber and the contractile apparatus. Similarly, it can be assumed that some structure also exists near the M-band, linked to the membrane and forming a convexity similar to costamere near the Z-line.

This assumption is confirmed by the data obtained from the fiber treated with Triton, where the Z-line, M-band and semi-sarcomere surface are nearly the same in height (Fig. 3).

\subsection{The transversal stiffness of skeletal muscle fibers}

\subsubsection{Rat}

The results in the following section 3.2.1 were described in details earlier (Ogneva, 2010). 

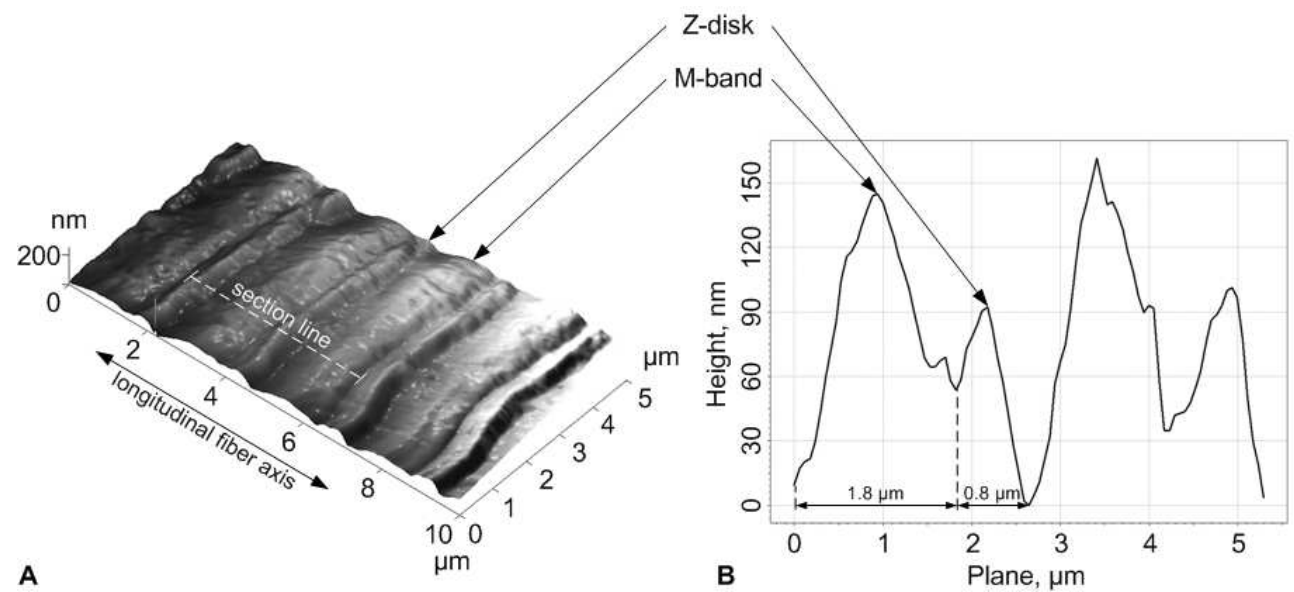

Fig. 2. 3D AFM area scan $(A)$ and a surface profile $(B)$ along a section line shown in $A$ of a permeabilized fiber from rat soleus muscle in relaxed state. There two kinds of humps on a surface profile. One of them correspond to the A-bands (1.8 $\mu \mathrm{m}$ in length) with the M-bands in the middle. Other humps correspond to the I-bands $(0.8 \mu \mathrm{m}$ in length) with the Z-disks in the middle. (Ogneva, 2010)

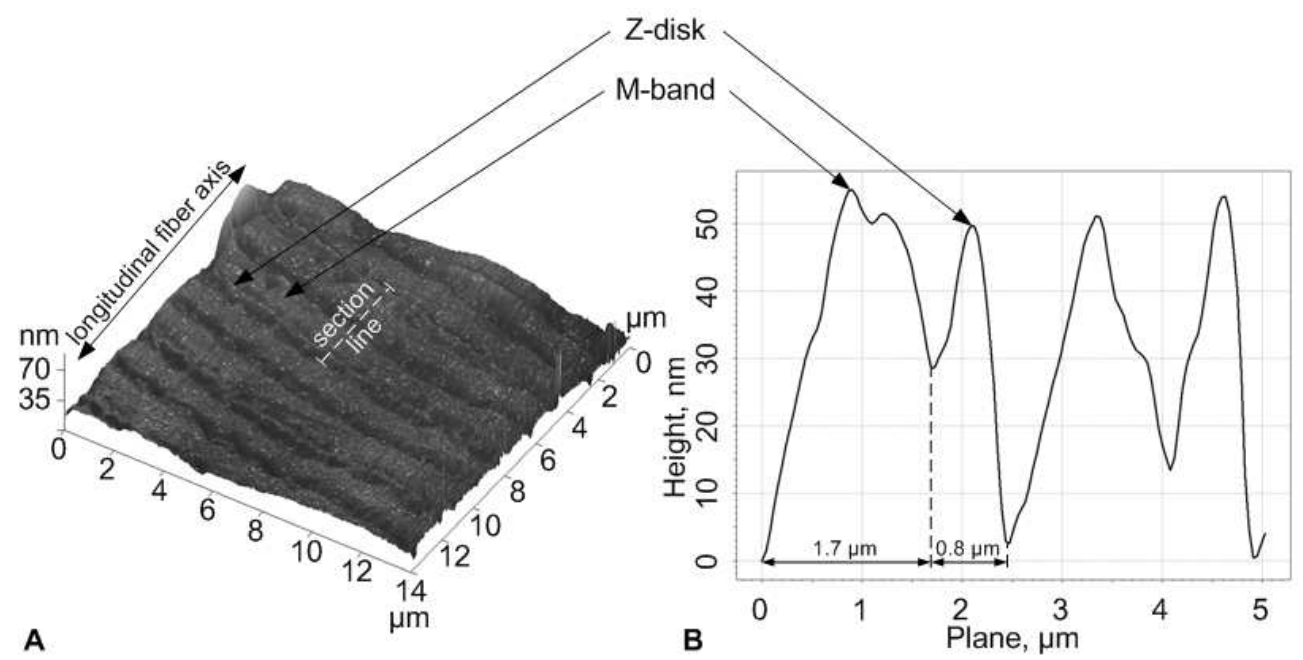

Fig. 3. 3D AFM area scan (A) and a surface profile (B) along a section line of Triton-treated muscle fiber in relaxed state. After Triton X-100 treatment the height of the Z-disk and Mband humps decreases compared to those in Fig. 2. (Ogneva, 2010)

\subsubsection{Sol}

The changes of transversal stiffness at various are as of the contractile apparatus in the course of gravitational unloading is provided in Table 1. In the control group, the transversal stiffness of the contractile apparatus of fibers of the soleus muscle near the semi- 
sarcomere, i.e. between the Z-disk and the M-band increases in the sequence relaxationactivation-rigor. The increase of this parameter is reliable both from relaxation to activation and from activation to rigor. This situation does not change after one day of gravitational unloading. However, in three days, the stiffness of the contractile apparatus reliably decreases near the semi-sarcomere both in the relaxed and in the activated/rigor states compared to similar states in the control group. This decrease is even more prominent seven days after antiorthostatic suspension. The minimum stiffness value compared to the control level is reached 12 days after the gravitational unloading. Nevertheless, after three, seven and twelve days of suspension, the stiffness of the semi-sarcomere when contraction is activated does reliably increase, just like in the rigor state compared to the activated calcium.

\begin{tabular}{|c|c|c|c|}
\hline Group State & Relaxed & $\begin{array}{l}\text { Activated } \\
(\mathrm{pCa}=4.2)\end{array}$ & Rigor \\
\hline \multicolumn{4}{|c|}{ Transversal stiffness of the half-sarcomere area $k_{\perp c a}$} \\
\hline Control & $2.92 \pm 0.16$ & $5.30 \pm 0.11^{@}$ & $7.22 \pm 0.13^{@ / \$}$ \\
\hline 1-HS & $2.79 \pm 0.17$ & $5.44 \pm 0.21^{@}$ & $6.98 \pm 0.17 @ / \$$ \\
\hline 3-HS & $1.90 \pm 0.10^{*}$ & $2.84 \pm 0.22 * / @$ & $5.55 \pm 0.29 * / @ / \$$ \\
\hline 7-HS & $1.35 \pm 0.12^{*}$ & $2.10 \pm 0.15 * / @$ & $4.35 \pm 0.21^{* / @ / \$}$ \\
\hline 12-HS & $0.93 \pm 0.14^{*}$ & $1.92 \pm 0.12 * / @$ & $3.42 \pm 0.17^{* / @ / \$ ~}$ \\
\hline \multicolumn{4}{|c|}{ Transversal stiffness of the M-band area $k_{\perp M l}$} \\
\hline Control & $3.68 \pm 0.09$ & $7.91 \pm 0.29 @$ & $10.32 \pm 0.17 @ / \$$ \\
\hline 1-HS & $3.46 \pm 0.11$ & $7.23 \pm 0.29 @$ & $9.6 \pm 0.3^{\circledR / \$}$ \\
\hline 3-HS & $3.01 \pm 0.20^{*}$ & $4.1 \pm 0.1^{* / @ ~}$ & $7.27 \pm 0.28^{* / @ / \$}$ \\
\hline 7-HS & $2.95 \pm 0.29^{*}$ & $3.80 \pm 0.21 * / @$ & $6.02 \pm 0.27^{* / @ / \$}$ \\
\hline 12-HS & $1.82 \pm 0.13^{*}$ & $2.80 \pm 0.21^{* / @ ~}$ & $5.3 \pm 0.3^{* / @ / \$}$ \\
\hline \multicolumn{4}{|c|}{ Transversal stiffness of the Z-disk area $k_{\perp Z d}$} \\
\hline Control & $8.21 \pm 0.23$ & $11.27 \pm 0.27^{@}$ & $12.92 \pm 0.23 @ / \$$ \\
\hline 1-HS & $7.82 \pm 0.11$ & $11.10 \pm 0.23^{@}$ & $10.83 \pm 0.17 @ / \$$ \\
\hline 3-HS & $3.22 \pm 0.15^{*}$ & $7.24 \pm 0.13^{* / @ ~}$ & $8.42 \pm 0.15^{* / @ / \$ ~}$ \\
\hline 7-HS & $2.48 \pm 0.17^{*}$ & $4.31 \pm 0.23^{* / @ ~}$ & $5.29 \pm 0.13 * / @ / \$$ \\
\hline 12-HS & $2.12 \pm 0.09^{*}$ & $3.45 \pm 0.23 * / @$ & $4.63 \pm 0.15 * / @ / \$$ \\
\hline
\end{tabular}

Table 1. Transversal stiffness $(\mathrm{pN} / \mathrm{nm})$ of isolated rat's Triton-treated Sol muscle fibers in liquid in relaxed, calcium activated $(\mathrm{pCa}=4.2)$ and rigor states under gravitational unloading. * - p<0.05 as compared to the analogous state of the group «Control», @ - p<0.05 as compared to the relaxed state at the same group, $\$-\mathrm{p}<0.05$ as compared to the activated state at the same group. (Ogneva, 2010)

Near the M-band, the stiffness of the contractile apparatus of fibers of the soleus muscle is higher than the stiffness of the semi-sarcomere. The trends of gravitational unloading described for the area of the semi-sarcomere are also valid for the M-band, although its stiffness in activation and rigor stages does not increase as much as in the semi-sarcomere.

The transversal stiffness of the Z-disk is significantly higher than in the semi-sarcomere and the M-band. It also, just like described above, increases during activation and rigor, 
although less intensively. Furthermore, the changes of the transversal stiffness of the Z-disk in the course of gravitational unloading are the same as after three days of suspension. However, these changes are much more prominent than in the area of the semi-sarcomere and the M-band.

The transversal stiffness of various segments of glycerynized fibers of the soleus muscle of rat (Table 2) in the control group increases during the activation of contraction compared to the relaxed state and when transitioning to rigor compared to the activated state. However, the intensity of this increase is not as significant as in demembranated fiber, which is especially prominent when the stiffness of sarcolemma slightly increases between the projections of the Z-disk and M-band when contraction is activated compared to the increase of stiffness near the semi-sarcomere in a similar situation. It should be noted that in the relaxed state, the stiffness of this part of sarcolemma and the semi-sarcomere are comparable. When contraction is activated, the stiffness of sarcolemma in the projections of the Z-disk and M-band are increased more considerably; moreover, in the relaxed state, the stiffness values of this type of muscle fiber is significantly lower than of the Z-disk and M-band of the contraction apparatus.

\begin{tabular}{|c|c|c|c|}
\hline Group $\quad$ State & Relaxed & $\begin{array}{l}\text { Activated } \\
(\mathrm{pCa}=4.2)\end{array}$ & Rigor \\
\hline \multicolumn{4}{|c|}{ Transversal stiffness of sarcolemma between the M-band and Z-disk projections $k_{\perp s}$} \\
\hline Control & $3.05 \pm 0.03$ & $3.19 \pm 0.06^{@}$ & $3.6 \pm 0.09 @ / \$$ \\
\hline 1-HS & $1.25 \pm 0.07^{*}$ & $1.38 \pm 0.09^{*}$ & $1.49 \pm 0.08^{* / @ ~}$ \\
\hline 3-HS & $0.78 \pm 0.08^{*}$ & $0.87 \pm 0.12^{*}$ & $0.99 \pm 0.13^{*}$ \\
\hline 7-HS & $0.43 \pm 0.06^{*}$ & $0.54 \pm 0.04^{*}$ & $0.56 \pm 0.04^{*}$ \\
\hline 12-HS & $0.84 \pm 0.08^{*}$ & $1.01 \pm 0.14^{*}$ & $0.91 \pm 0.06^{*}$ \\
\hline \multicolumn{4}{|c|}{ Transversal stiffness of sarcolemma at the M-band projection $k_{\perp M l s}$} \\
\hline Control & $1.98 \pm 0.07$ & $2.65 \pm 0.14^{@}$ & $3.02 \pm 0.11^{@ / \$}$ \\
\hline 1-HS & $1.89 \pm 0.11^{*}$ & $2.5 \pm 0.3^{* / @}$ & $3.09 \pm 0.15 * / @ / \$$ \\
\hline 3-HS & $1.77 \pm 0.08^{*}$ & $2.16 \pm 0.11^{* / @ ~}$ & $2.68 \pm 0.14^{* / @ ~}$ \\
\hline 7-HS & $1.05 \pm 0.12^{*}$ & $1.16 \pm 0.16^{*}$ & $1.38 \pm 0.17^{*}$ \\
\hline 12-HS & $1.08 \pm 0.09^{*}$ & $1.48 \pm 0.17^{* / @ ~}$ & $1.92 \pm 0.16^{* / @ / \$}$ \\
\hline \multicolumn{4}{|c|}{ Transversal stiffness of sarcolemma at the Z-disk projection $k_{\perp Z d s}$} \\
\hline Control & $3.08 \pm 0.14$ & $3.42 \pm 0.21^{@}$ & $3.92 \pm 0.13^{@ / \$}$ \\
\hline 1-HS & $2.21 \pm 0.22^{*}$ & $2.84 \pm 0.16^{* / @ ~}$ & $3.13 \pm 0.21 * / @$ \\
\hline 3-HS & $1.13 \pm 0.12^{*}$ & $1.53 \pm 0.14^{* / @ ~}$ & $1.93 \pm 0.18^{* / @ ~}$ \\
\hline 7-HS & $0.91 \pm 0.05^{*}$ & $1.21 \pm 0.11^{* / @ ~}$ & $1.31 \pm 0.09 * / @$ \\
\hline 12-HS & $1.32 \pm 0.12^{*}$ & $1.83 \pm 0.13 * / @$ & 2.01土0.12*/@ \\
\hline
\end{tabular}

Table 2. Transversal stiffness $(\mathrm{pN} / \mathrm{nm}$ ) of isolated rat's permeabilized Sol muscle fibers in liquid in relaxed, calcium activated $(\mathrm{pCa}=4.2)$ and rigor states under gravitational unloading. * - p<0.05 as compared to the analogous state of the group «Control», $₫$ - $p<0.05$ as compared to the relaxed state at the same group, $\$-\mathrm{p}<0.05$ as compared to the activated state at the same group. (Ogneva, 2010)

After one day of gravitational unloading, the stiffness of all parts of sarcolemma both in the relaxed and activated state is decreased compared to the similar state in the control group, 
reaching the minimum after seven days of suspension and tending to increase by the twelfth day of gravitational unloading. However, when the contraction is activated and in rigor the stiffness of sarcolemma between the projections of the Z-disk and the M-band is reliably similar as early as after one day of gravitational unloading. A similar situation may take place up to the twelfth day of antiorthostatic suspension. The transversal stiffness of the sarcolemma in the area of the projection of the Z-disk and the M-band is increased when the contraction is activated during the gravitational unloading, although not as significantly as in the control group.

\subsubsection{MG}

The transversal stiffness of various areas of the contractile apparatus of fibers of the medial gastrocnemius muscle (Table 3 ) is almost twice as low as the same values for fibers of the soleus muscle in the relaxed, activated and rigor states. However, the increase of transversal stiffness in the sequence semi-sarcomere - M-band - Z-disk takes places just like in the fibers of the soleus muscle.

\begin{tabular}{|c|c|c|c|}
\hline Group State & Relaxed & $\begin{array}{l}\text { Activated } \\
(\mathrm{pCa}=4.2)\end{array}$ & Rigor \\
\hline \multicolumn{4}{|c|}{ Transversal stiffness of the half-sarcomere area $k_{\perp c a}$} \\
\hline Control & $1.56 \pm 0.16$ & $2.25 \pm 0.18^{\circledR}$ & $3.43 \pm 0.23^{@ / \$}$ \\
\hline 1-HS & $2.80 \pm 0.13^{*}$ & $3.65 \pm 0.29 * / @$ & $4.17 \pm 0.22 * / @ / \$$ \\
\hline 3-HS & $2.38 \pm 0.14^{*}$ & $2.90 \pm 0.17^{@}$ & $3.57 \pm 0.19 @ / \$$ \\
\hline 7-HS & $2.07 \pm 0.12$ & $2.46 \pm 0.15^{@}$ & $3.47 \pm 0.24^{@ / \$}$ \\
\hline 12-HS & $1.65 \pm 0.06$ & $2.56 \pm 0.12^{@}$ & $3.42 \pm 0.20 @ / \$$ \\
\hline \multicolumn{4}{|c|}{ Transversal stiffness of the M-band area $k_{\perp M l}$} \\
\hline Control & $2.54 \pm 0.16$ & $3.74 \pm 0.19 @$ & $4.80 \pm 0.27 @ / \$$ \\
\hline 1-HS & $4.12 \pm 0.21^{*}$ & $5.08 \pm 0.24 * / @$ & $6.52 \pm 0.19 * / @ / \$$ \\
\hline $3-\mathrm{HS}$ & $2.98 \pm 0.25$ & $3.60 \pm 0.15^{@}$ & $5.69 \pm 0.13^{@ / \$}$ \\
\hline 7-HS & $2.72 \pm 0.14$ & $3.39 \pm 0.26^{@}$ & $5.50 \pm 0.28 @ / \$$ \\
\hline 12-HS & $2.22 \pm 0.18$ & $3.47 \pm 0.14^{@}$ & $6.01 \pm 0.26^{@ / \$}$ \\
\hline \multicolumn{4}{|c|}{ Transversal stiffness of the Z-disk area $k_{\perp Z d}$} \\
\hline Control & $3.87 \pm 0.29$ & $5.94 \pm 0.22^{@}$ & $7.54 \pm 0.24^{@ / \$}$ \\
\hline 1-HS & $5.7 \pm 0.3^{*}$ & $7.7 \pm 0.4^{* / @ ~}$ & $9.7 \pm 0.5^{* / @ / \$}$ \\
\hline 3-HS & $4.9 \pm 0.5^{*}$ & $6.8 \pm 0.4^{* / @ ~}$ & $8.0 \pm 0.6^{@ / \$}$ \\
\hline 7-HS & $3.80 \pm 0.14$ & $5.5 \pm 0.6^{@}$ & $7.3 \pm 0.3^{\circledR / \$}$ \\
\hline 12-HS & $3.51 \pm 0.19$ & $5.7 \pm 0.6^{@}$ & $7.2 \pm 0.5^{@ / \$}$ \\
\hline
\end{tabular}

Table 3. Transversal stiffness $(\mathrm{pN} / \mathrm{nm})$ of isolated rat's Triton-treated $M G$ muscle fibers in liquid in relaxed, calcium activated $(\mathrm{pCa}=4.2)$ and rigor states under gravitational unloading. * - p<0.05 as compared to the analogous state of the group «Control», ${ }^{\circledR}-\mathrm{p}<0.05$ as compared to the relaxed state at the same group, $\$-\mathrm{p}<0.05$ as compared to the activated state at the same group. (Ogneva, 2010)

During the gravitational unloading, except early stages, the transversal stiffness values of the semi-sarcomere, Z-disk and M-band do not show any reliable changes in all of the studied states. At early stages (one day and three days), there is a reliable increase of the 
transversal stiffness of the semi-sarcomere and the Z-disk, which is more pronounced during the first day of suspension. Moreover, the increase of transversal stiffness of the Mband takes place only during the first day.

Unlike the contractile apparatus, the transversal stiffness of the sarcolemma (Table 4) in the area between the projections of the Z-disk and the M-band starts to decrease as early as after one day of gravitational unloading and continues to decrease during the whole suspension period. The stiffness of the sarcolemma during activation and rigor increases in the control group after one day of functional unloading, but after three days, there are no changes in the stiffness of this segment of the sarcolemma when contraction is activated and when transitioning to the rigor state compared to the stiffness in the relaxed state. The transversal stiffness of the sarcolemma in the M-band projection increases during the first day of gravitational unloading both in the relaxed and in the activated state compared to the fibers of the control group in a similar state, although there are no reliable differences between the relaxed and activated state. Seven days after the unloading, the stiffness values in different states are not different from the control group. A similar situation occurs in sarcolemma in the area of the Z-disk projection. However, after 12 days of suspension, the transversal stiffness of this part of sarcolemma reliably decreases compared to the control group.

\begin{tabular}{|c|c|c|c|}
\hline Group State & Relaxed & $\begin{array}{l}\text { Activated } \\
(\mathrm{pCa}=4.2)\end{array}$ & Rigor \\
\hline \multicolumn{4}{|c|}{ Transversal stiffness of sarcolemma between the M-band and Z-disk projections $k_{\perp s}$} \\
\hline Control & $2.87 \pm 0.12$ & $3.01 \pm 0.21^{@}$ & $3.26 \pm 0.14^{@ / \$}$ \\
\hline 1-HS & $2.21 \pm 0.08^{*}$ & $2.38 \pm 0.09^{* / @ ~}$ & $2.69 \pm 0.24^{* / @ ~}$ \\
\hline 3-HS & $2.12 \pm 0.10^{*}$ & $2.34 \pm 0.17^{*}$ & $2.27 \pm 0.14^{*}$ \\
\hline 7-HS & $1.91 \pm 0.09^{*}$ & $2.11 \pm 0.11^{*}$ & $2.32 \pm 0.11^{*}$ \\
\hline 12-HS & $2.11 \pm 0.13^{*}$ & $2.29 \pm 0.18^{*}$ & $2.08 \pm 0.13^{*}$ \\
\hline \multicolumn{4}{|c|}{ Transversal stiffness of sarcolemma at the M-band projection $k_{\perp M l s}$} \\
\hline Control & $1.53 \pm 0.07$ & $1.87 \pm 0.13^{@}$ & $2.21 \pm 0.16^{@ / \$}$ \\
\hline 1-HS & $2.12 \pm 0.09^{*}$ & $2.31 \pm 0.14^{*}$ & $2.55 \pm 0.13^{* / @ ~}$ \\
\hline 3-HS & $1.75 \pm 0.15$ & $1.95 \pm 0.14^{*}$ & $2.43 \pm 0.13^{* / @ / \$ ~}$ \\
\hline 7-HS & $1.57 \pm 0.09$ & $1.73 \pm 0.11^{@}$ & $2.13 \pm 0.16^{@ / \$}$ \\
\hline 12-HS & $1.26 \pm 0.12$ & $1.64 \pm 0.11^{@}$ & $2.01 \pm 0.19^{@ / \$}$ \\
\hline \multicolumn{4}{|c|}{ Transversal stiffness of sarcolemma at the Z-disk projection $k_{\perp Z d s}$} \\
\hline Control & $2.24 \pm 0.18$ & $2.74 \pm 0.25^{@}$ & $3.17 \pm 0.14^{@ / \$}$ \\
\hline 1-HS & $2.91 \pm 0.11^{*}$ & $3.12 \pm 0.19^{*}$ & $3.47 \pm 0.26^{* / @}$ \\
\hline 3-HS & $2.69 \pm 0.27$ & $3.14 \pm 0.21^{@}$ & $3.38 \pm 0.13^{@}$ \\
\hline 7-HS & $2.25 \pm 0.13$ & $2.7 \pm 0.3^{@}$ & $3.12 \pm 0.21^{@}$ \\
\hline 12-HS & $1.84 \pm 0.08^{*}$ & $2.17 \pm 0.26^{*}$ & $2.35 \pm 0.19^{*}$ \\
\hline
\end{tabular}

Table 4. Transversal stiffness ( $\mathrm{pN} / \mathrm{nm}$ ) of isolated rat's permeabilized MG muscle fibers in liquid in relaxed, calcium activated $(\mathrm{pCa}=4.2)$ and rigor states under gravitational unloading. * - p<0.05 as compared to the analogous state of the group «Control», @ - $p<0.05$ as compared to the relaxed state at the same group, $\$-\mathrm{p}<0.05$ as compared to the activated state at the same group. (Ogneva, 2010) 


\subsubsection{TA}

The transversal stiffness of various segments of the contractile apparatus of fibers of the tibialis anterior muscle (Table 5) when activating the contraction and transitioning to the rigor state changes just like that of the soleus muscle in the control group.

\begin{tabular}{|c|c|c|c|}
\hline Group $\quad$ State & Relaxed & $\begin{array}{l}\text { Activated } \\
(\mathrm{pCa}=4.2)\end{array}$ & Rigor \\
\hline \multicolumn{4}{|c|}{ Transversal stiffness of the half-sarcomere area $k_{\perp c a}$} \\
\hline Control & $2.13 \pm 0.18$ & $4.12 \pm 0.26^{@}$ & $5.1 \pm 0.3^{\circledR / \$}$ \\
\hline 1-HS & $4.37 \pm 0.27^{*}$ & $5.7 \pm 0.3^{* / @ ~}$ & $7.4 \pm 0.3^{* / @ / \$}$ \\
\hline 3-HS & $3.87 \pm 0.11^{*}$ & $5.22 \pm 0.28^{* / @ ~}$ & $6.2 \pm 0.4^{* / @ / \$}$ \\
\hline 7-HS & $3.33 \pm 0.08^{*}$ & $5.24 \pm 0.26 * / @$ & $6.02 \pm 0.21^{* / @ / \$}$ \\
\hline 12-HS & $2.93 \pm 0.07^{*}$ & $5.11 \pm 0.22 * / @$ & $6.13 \pm 0.29 * / @ / \$$ \\
\hline \multicolumn{4}{|c|}{ Transversal stiffness of the M-band area $k_{\perp M l}$} \\
\hline Control & $2.23 \pm 0.27$ & $6.3 \pm 0.4^{@}$ & $7.7 \pm 0.4^{@ / \$}$ \\
\hline 1-HS & $5.25 \pm 0.21^{*}$ & $8.4 \pm 0.6^{* / @ ~}$ & $11.6 \pm 0.5^{* / @ / \$}$ \\
\hline 3-HS & $4.41 \pm 0.29^{*}$ & $7.90 \pm 0.24^{* / @ ~}$ & $8.63 \pm 0.29 * / @ / \$$ \\
\hline 7-HS & $3.93 \pm 0.28^{*}$ & $7.15 \pm 0.26 * / @$ & $8.42 \pm 0.28 * / @ / \$$ \\
\hline 12-HS & $3.23 \pm 0.25^{*}$ & $7.48 \pm 0.29 * / @$ & $8.9 \pm 0.4^{* / @ / \$ ~}$ \\
\hline \multicolumn{4}{|c|}{ Transversal stiffness of the Z-disk area $k_{\perp Z d}$} \\
\hline Control & $6.52 \pm 0.23$ & $8.9 \pm 0.6^{@}$ & $10.6 \pm 0.7^{@ / \$}$ \\
\hline 1-HS & $8.1 \pm 0.5^{*}$ & $10.3 \pm 0.3^{* / @ ~}$ & $14.7 \pm 0.5^{* / @ / \$ ~}$ \\
\hline 3-HS & $8.2 \pm 0.4^{*}$ & $9.7 \pm 0.7 * / @$ & $11.8 \pm 0.6^{* / @ / \$ ~}$ \\
\hline 7-HS & $7.7 \pm 0.4$ & $9.5 \pm 0.4^{@}$ & $11.4 \pm 0.3^{@ / \$}$ \\
\hline $12-\mathrm{HS}$ & $6.9 \pm 0.5$ & $9.2 \pm 0.5^{@}$ & $11.5 \pm 0.3^{\circledR / \$}$ \\
\hline
\end{tabular}

Table 5. Transversal stiffness $(\mathrm{pN} / \mathrm{nm})$ of isolated rat's Triton-treated TA muscle fibers in liquid in relaxed, calcium activated $(\mathrm{pCa}=4.2)$ and rigor states under gravitational unloading. * - p $<0.05$ as compared to the analogous state of the group «Control», @ - $p<0.05$ as compared to the relaxed state at the same group, $\$-p<0.05$ as compared to the activated state at the same group. (Ogneva, 2010)

However, after one day of gravitational unloading, the transversal stiffness near the semisarcomere significantly increases and then starts decreasing, although it fails to reach the control group values and still remains increased by the twelfth day, not only in the relaxed, but in the activated and rigor state as well. A similar situation is observed at the M-band of the contractile apparatus. The stiffness of the Z-disk exceeds the control level after one day and after three days of gravitational disuse, but by the seventh day the values are practically not different from the control values.

The transversal stiffness of the sarcolemma (Table 6) between the Z-disk and M-band projections does not change when contraction is activated and in rigor, unlike the soleus muscle. In the course of gravitational unloading, the stiffness of this part of sarcolemma reliably decreases one day after the antiorthostatic suspension, returning to the control value after 7 days of gravitational unloading. At the same time, the transversal stiffness of the sarcolemma at the M-band projection does not change during the suspension, although 
there is no difference between the values in the activated and rigor states. The increase of the transversal stiffness of the sarcolemma at the Z-disk projection is observed after three and seven days of functional unloading, while by the twelfth day the values return to the control level.

\begin{tabular}{|c|c|c|c|}
\hline Group State & Relaxed & $\begin{array}{l}\text { Activated } \\
(\mathrm{pCa}=4.2)\end{array}$ & Rigor \\
\hline \multicolumn{4}{|c|}{ Transversal stiffness of sarcolemma between the M-band and Z-disk projections $k_{\perp s}$} \\
\hline Control & $3.56 \pm 0.28$ & $3.21 \pm 0.21$ & $3.19 \pm 0.20$ \\
\hline 1-HS & $2.46 \pm 0.13^{*}$ & $2.31 \pm 0.11^{*}$ & $2.26 \pm 0.14^{*}$ \\
\hline 3-HS & $2.86 \pm 0.27$ & $2.93 \pm 0.26$ & $3.01 \pm 0.16$ \\
\hline 7-HS & $3.95 \pm 0.18$ & $4.01 \pm 0.12$ & $3.84 \pm 0.19$ \\
\hline 12-HS & $4.03 \pm 0.21$ & $3.58 \pm 0.17$ & $3.64 \pm 0.16$ \\
\hline \multicolumn{4}{|c|}{ Transversal stiffness of sarcolemma at the M-band projection $k_{\perp M l s}$} \\
\hline Control & $1.43 \pm 0.26$ & $2.45 \pm 0.25^{@}$ & $2.78 \pm 0.09 @$ \\
\hline 1-HS & $2.14 \pm 0.27$ & $2.55 \pm 0.3^{\circledR}$ & $2.98 \pm 0.14^{@}$ \\
\hline 3-HS & $2.21 \pm 0.19$ & $2.83 \pm 0.27 @$ & $3.04 \pm 0.23^{\circledR}$ \\
\hline 7-HS & $2.18 \pm 0.23$ & $2.93 \pm 0.29 @$ & $3.17 \pm 0.28 @$ \\
\hline 12-HS & $2.01 \pm 0.18$ & $3.14 \pm 0.21^{@}$ & $3.25 \pm 0.22 @$ \\
\hline \multicolumn{4}{|c|}{ Transversal stiffness of sarcolemma at the Z-disk projection $k_{\perp Z d s}$} \\
\hline Control & $2.98 \pm 0.29$ & $3.47 \pm 0.23$ & $3.71 \pm 0.13^{\circledR}$ \\
\hline 1-HS & $3.45 \pm 0.26$ & $3.76 \pm 0.25$ & $4.13 \pm 0.18^{@}$ \\
\hline 3-HS & $3.81 \pm 0.24^{*}$ & $4.31 \pm 0.23^{*}$ & $4.41 \pm 0.28^{*}$ \\
\hline 7-HS & $3.71 \pm 0.27^{*}$ & $4.14 \pm 0.23^{*}$ & $4.28 \pm 0.18^{*}$ \\
\hline 12-HS & $3.37 \pm 0.26$ & $3.88 \pm 0.25$ & $4.12 \pm 0.24$ \\
\hline
\end{tabular}

Table 6. Transversal stiffness $(\mathrm{pN} / \mathrm{nm})$ of isolated rat's permeabilized TA muscle fibers in liquid in relaxed, calcium activated $(\mathrm{pCa}=4.2)$ and rigor states under gravitational unloading. * - p $<0.05$ as compared to the analogous state of the group «Control», @ - p<0.05 as compared to the relaxed state at the same group, $\$-\mathrm{p}<0.05$ as compared to the activated state at the same group. (Ogneva, 2010)

\subsubsection{Mongolian gerbil}

\subsubsection{Sol}

Changes of the transversal stiffness of the contractile apparatus (Table 7) are similar to those of rat, but occur on the seventh, rather than on the third day of gravitational unloading. The reduction of stiffness of the contractile apparatus occurs in sync between all of its segments, but just like in rats, it is more prominent at the Z-disk. The trend of increasing stiffness as a result of activation of contraction and rigor persists at all stages of the gravitational unloading. At the same time, the depth of stiffness changes in Mongloian gerbil is not as considerable as in rats. 


\begin{tabular}{|c|c|c|c|}
\hline Group $\quad$ State & Relaxed & $\begin{array}{l}\text { Activated } \\
(\mathrm{pCa}=4.2)\end{array}$ & Rigor \\
\hline \multicolumn{4}{|c|}{ Transversal stiffness of the half-sarcomere area $k_{\perp c a}$} \\
\hline Control & $2.3 \pm 0.4$ & $5.5 \pm 0.7^{@}$ & $7.8 \pm 0.4^{@ / \$}$ \\
\hline 1-HS & $2.40 \pm 0.15$ & $5.2 \pm 0.3^{@}$ & $7.6 \pm 0.5^{@ / \$}$ \\
\hline 3-HS & $2.21 \pm 0.18$ & $4.8 \pm 0.5^{@}$ & $6.5 \pm 0.3^{\circledR / \$}$ \\
\hline 7-HS & $1.53 \pm 0.14^{*}$ & $3.6 \pm 0.5^{* / @}$ & $4.3 \pm 0.3^{* / @ / \$ ~}$ \\
\hline 12-HS & $1.18 \pm 0.04^{*}$ & $2.30 \pm 0.13^{* / @ ~}$ & $2.61 \pm 0.12 * / @ / \$$ \\
\hline \multicolumn{4}{|c|}{ Transversal stiffness of the M-band area $k_{\perp M l}$} \\
\hline Control & $4.6 \pm 0.6$ & $7.8 \pm 0.6^{@}$ & $12.6 \pm 0.6^{\circledR / \$}$ \\
\hline 1-HS & $4.5 \pm 0.7$ & $7.1 \pm 0.6^{@}$ & $11.3 \pm 0.7 @ / \$$ \\
\hline 3-HS & $4.7 \pm 0.5$ & $6.5 \pm 0.3^{@}$ & $9.4 \pm 0.8^{@ / \$}$ \\
\hline 7-HS & $2.96 \pm 0.25^{*}$ & $5.2 \pm 0.4^{* / @ ~}$ & $6.3 \pm 0.7^{* / @ / \$}$ \\
\hline 12-HS & $1.9 \pm 0.3^{*}$ & $2.50 \pm 0.27 * / @$ & $3.8 \pm 0.4^{* / @ / \$}$ \\
\hline \multicolumn{4}{|c|}{ Transversal stiffness of the Z-disk area $k_{\perp Z d}$} \\
\hline Control & $7.4 \pm 0.9$ & $11.4 \pm 1.5^{@}$ & $15.4 \pm 0.9^{\circledR / \$}$ \\
\hline 1-HS & $7.1 \pm 0.6$ & $10.8 \pm 0.4^{@}$ & $13.3 \pm 2.1^{@ / \$}$ \\
\hline 3-HS & $6.3 \pm 0.5$ & $9.2 \pm 0.8^{\circledR}$ & $13.6 \pm 1.8^{\circledR / \$}$ \\
\hline 7-HS & $3.15 \pm 0.29^{*}$ & $5.2 \pm 0.6^{* / @}$ & $7.0 \pm 0.6^{* / @ / \$}$ \\
\hline 12-HS & $2.6 \pm 0.3^{*}$ & $3.6 \pm 0.4^{* / @ ~}$ & $4.2 \pm 0.5^{* / @ / \$ ~}$ \\
\hline
\end{tabular}

Table 7. Transversal stiffness $(\mathrm{pN} / \mathrm{nm})$ of isolated gerbil's Triton-treated Sol muscle fibers in liquid in relaxed, calcium activated $(\mathrm{pCa}=4.2)$ and rigor states under gravitational unloading. * - p<0.05 as compared to the analogous state of the group «Control», @ - p<0.05 as compared to the relaxed state at the same group, $\$-p<0.05$ as compared to the activated state at the same group.

The transversal stiffness of various segments of the sarcolemma (Table 8) of fibers of the soleus muscle of the Mongolian gerbil changes much earlier than the transversal stiffness of the contractile apparatus, one day after the gravitational unloading begins. Furthermore, while the effect of increased stiffness of the sarcolemma at the Z-disk projection and M-band in case of activation of contraction remains for the control group after one day of suspension, subsequently, with increased duration of hypokinesia, this trend was not observed.

\subsubsection{MG}

Changes in the transversal stiffness of some segments of the contractile apparatus of fibers of the gastrocnemius muscle of the Mongolian gerbil (Table 9) are similar to those of rats, but are considerably less prominent, although reliable. Thus, the increase of stiffness of the contractile apparatus between the Z-disk and the M-band occurs one day after the gravitational unloading, just like in rats. However, in rats, this parameter returns to the control value by the seventh day of suspension, but as early as by the third day in gerbils. Increase of stiffness of the Z-disk and the M-band is also reliable only in the first day of hypokinesia, while on the third day the transversal stiffness is not different from the control value. 


\begin{tabular}{|c|c|c|c|}
\hline Group State & Relaxed & $\begin{array}{l}\text { Activated } \\
(\mathrm{pCa}=4.2)\end{array}$ & Rigor \\
\hline \multicolumn{4}{|c|}{ Transversal stiffness of sarcolemma between the M-band and Z-disk projections $k_{\perp s}$} \\
\hline Control & $1.82 \pm 0.08$ & $1.83 \pm 0.11$ & $1.94 \pm 0.13$ \\
\hline 1-HS & $1.34 \pm 0.09^{*}$ & $1.47 \pm 0.25^{*}$ & $1.33 \pm 0.21^{*}$ \\
\hline 3-HS & $0.98 \pm 0.08^{*}$ & $1.06 \pm 0.22^{*}$ & $1.01 \pm 0.25^{*}$ \\
\hline 7-HS & $0.76 \pm 0.08^{*}$ & $0.81 \pm 0.19^{*}$ & $0.95 \pm 0.21^{*}$ \\
\hline 12-HS & $0.13 \pm 0.14^{*}$ & $0.15 \pm 0.08^{*}$ & $0.13 \pm 0.21^{*}$ \\
\hline \multicolumn{4}{|c|}{ Transversal stiffness of sarcolemma at the M-band projection $k_{\perp M l s}$} \\
\hline Control & $1.76 \pm 0.11$ & $2.13 \pm 0.12^{@}$ & $2.42 \pm 0.11^{@ / \$}$ \\
\hline 1-HS & $1.79 \pm 0.13$ & $2.05 \pm 0.23$ & $2.35 \pm 0.17 @$ \\
\hline 3-HS & $1.47 \pm 0.15^{*}$ & $1.59 \pm 0.21^{*}$ & $1.68 \pm 0.15^{*}$ \\
\hline 7-HS & $1.29 \pm 0.15^{*}$ & $1.62 \pm 0.22^{*}$ & $1.76 \pm 0.24^{*}$ \\
\hline 12-HS & $0.39 \pm 0.03^{*}$ & $0.41 \pm 0.04^{*}$ & $0.43 \pm 0.03^{*}$ \\
\hline \multicolumn{4}{|c|}{ Transversal stiffness of sarcolemma at the Z-disk projection $k_{\perp Z d s}$} \\
\hline Control & $2.39 \pm 0.18$ & $2.76 \pm 0.14^{@}$ & $3.12 \pm 0.12^{@ / \$}$ \\
\hline 1-HS & $2.01 \pm 0.12^{*}$ & $2.32 \pm 0.13^{\circledR}$ & $2.53 \pm 0.16^{* / @ ~}$ \\
\hline 3-HS & $1.53 \pm 0.29^{*}$ & $1.72 \pm 0.23^{*}$ & $1.87 \pm 0.19^{*}$ \\
\hline 7-HS & $1.63 \pm 0.23^{*}$ & $2.01 \pm 0.22^{*}$ & $2.34 \pm 0.24^{*}$ \\
\hline 12-HS & $0.49 \pm 0.06^{*}$ & $0.55 \pm 0.07^{*}$ & $0.52 \pm 0.07^{*}$ \\
\hline
\end{tabular}

Table 8. Transversal stiffness $(\mathrm{pN} / \mathrm{nm})$ of isolated gerbil's permeabilized Sol muscle fibers in liquid in relaxed, calcium activated $(\mathrm{pCa}=4.2)$ and rigor states under gravitational unloading. ${ }^{*}-\mathrm{p}<0.05$ as compared to the analogous state of the group «Control», $@-p<0.05$ as compared to the relaxed state at the same group, $\$-\mathrm{p}<0.05$ as compared to the activated state at the same group.

\begin{tabular}{|c|c|c|c|}
\hline Group $\quad$ State & Relaxed & $\begin{array}{l}\text { Activated } \\
(\mathrm{pCa}=4.2)\end{array}$ & Rigor \\
\hline \multicolumn{4}{|c|}{ Transversal stiffness of the half-sarcomere area $k_{\perp c a}$} \\
\hline Control & $1.67 \pm 0.14$ & $2.35 \pm 0.19 @$ & $4.5 \pm 0.3^{\circledR / \$}$ \\
\hline 1-HS & $2.71 \pm 0.15^{*}$ & $3.32 \pm 0.26^{* / @ ~}$ & $5.7 \pm 0.4^{*} / @ / \$$ \\
\hline 3-HS & $2.04 \pm 0.21$ & $3.09 \pm 0.27^{@}$ & $5.03 \pm 0.24^{@ / \$}$ \\
\hline 7-HS & $1.64 \pm 0.13$ & $2.84 \pm 0.27 @$ & $4.9 \pm 0.3^{@ / \$}$ \\
\hline 12-HS & $1.42 \pm 0.22$ & $2.41 \pm 0.22^{@}$ & $4.76 \pm 0.18^{@ / \$}$ \\
\hline \multicolumn{4}{|c|}{ Transversal stiffness of the M-band area $k_{\perp M l}$} \\
\hline Control & $2.68 \pm 0.24$ & $3.6 \pm 0.3^{@}$ & $5.4 \pm 0.3^{\circledR / \$}$ \\
\hline 1-HS & $4.11 \pm 0.14^{*}$ & $4.93 \pm 0.29 * / @$ & $6.10 \pm 0.29 * / @ / \$$ \\
\hline 3-HS & $2.64 \pm 0.28$ & $3.64 \pm 0.26^{@}$ & $5.70 \pm 0.23^{@ / \$}$ \\
\hline 7-HS & $2.60 \pm 0.27$ & $3.81 \pm 0.23^{@}$ & $5.40 \pm 0.27 @ / \$$ \\
\hline 12-HS & $2.4 \pm 0.3$ & $3.92 \pm 0.27 @$ & $5.19 \pm 0.29 @ / \$$ \\
\hline \multicolumn{4}{|c|}{ Transversal stiffness of the Z-disk area $k_{\perp Z d}$} \\
\hline Control & $4.03 \pm 0.23$ & $6.1 \pm 0.3^{@}$ & $9.5 \pm 0.4^{\circledR / \$}$ \\
\hline 1-HS & $5.4 \pm 0.6^{*}$ & $7.04 \pm 0.27 @$ & $11.3 \pm 0.7 @ / \$$ \\
\hline
\end{tabular}




\begin{tabular}{|c|c|c|c|}
\hline Group & Relaxed & $\begin{array}{c}\text { Activated } \\
(\mathrm{pCa}=4.2)\end{array}$ & Rigor \\
\hline 3-HS & $5.11 \pm 0.29$ & $6.3 \pm 0.3^{\circledR}$ & $8.9 \pm 0.5^{\circledR} / \$$ \\
\hline 7-HS & $4.4 \pm 0.4$ & $5.9 \pm 0.6^{\circledR}$ & $9.7 \pm 0.6^{\circledR /} \$$ \\
\hline 12-HS & $4.3 \pm 0.3$ & $6.20 \pm 0.29^{\circledR}$ & $9.3 \pm 0.5^{\circledR /} /$ \\
\hline
\end{tabular}

Table 9. Transversal stiffness $(\mathrm{pN} / \mathrm{nm})$ of isolated gerbil's Triton-treated $M G$ muscle fibers in liquid in relaxed, calcium activated $(\mathrm{pCa}=4.2)$ and rigor states under gravitational unloading. * - p<0.05 as compared to the analogous state of the group «Control», @ - p<0.05 as compared to the relaxed state at the same group, $\$-\mathrm{p}<0.05$ as compared to the activated state at the same group.

The transversal stiffness of the sarcolemma (Table 10) between the Z-disk and M-band projections is only decreased relative to the control level during the first day of unloading, but does not differ from the control values afterwards. An increase of the transversal stiffness is observed from the first up to the seventh day of unloading near the sarcolemma at the Z-disk projection in Mongolian gerbils, unlike in rats; there were no significant changes at the M-band at any stage of suspension. Furthermore, the transversal stiffness of the sarcolemma at the Z-disk projection reliably increases by the activation compared to the relaxed state within the unloading of any studied length, while after seven days of suspension a difference between the activated and rigor state is also observed.

\begin{tabular}{|c|c|c|c|}
\hline Group State & Relaxed & $\begin{array}{l}\text { Activated } \\
(\mathrm{pCa}=4.2)\end{array}$ & Rigor \\
\hline \multicolumn{4}{|c|}{ Transversal stiffness of sarcolemma between the M-band and Z-disk projections $k_{\perp s}$} \\
\hline Control & $1.54 \pm 0.21$ & $1.60 \pm 0.11$ & $1.79 \pm 0.13$ \\
\hline 1-HS & $1.08 \pm 0.09^{*}$ & $1.29 \pm 0.08 * / @$ & $1.51 \pm 0.12 * / @ / \$$ \\
\hline 3-HS & $1.43 \pm 0.15$ & $1.63 \pm 0.13$ & $1.71 \pm 0.19$ \\
\hline 7-HS & $1.34 \pm 0.14$ & $1.45 \pm 0.09$ & $1.52 \pm 0.11$ \\
\hline 12-HS & $1.13 \pm 0.17$ & $1.28 \pm 0.13$ & $1.39 \pm 0.19$ \\
\hline \multicolumn{4}{|c|}{ Transversal stiffness of sarcolemma at the M-band projection $k_{\perp M l s}$} \\
\hline Control & $1.33 \pm 0.13$ & $1.62 \pm 0.12^{@}$ & $1.84 \pm 0.15^{@}$ \\
\hline 1-HS & $1.39 \pm 0.21$ & $1.41 \pm 0.13$ & $1.52 \pm 0.19$ \\
\hline 3-HS & $1.53 \pm 0.11$ & $1.71 \pm 0.12$ & $1.95 \pm 0.15$ \\
\hline 7-HS & $1.34 \pm 0.15$ & $1.53 \pm 0.12$ & $1.88 \pm 0.16$ \\
\hline 12-HS & $1.02 \pm 0.11$ & $1.17 \pm 0.08$ & $1.32 \pm 0.12$ \\
\hline \multicolumn{4}{|c|}{ Transversal stiffness of sarcolemma at the Z-disk projection $k_{\perp Z d s}$} \\
\hline Control & $1.86 \pm 0.11$ & $2.27 \pm 0.09 @$ & $2.62 \pm 0.07^{@ / \$}$ \\
\hline 1-HS & $2.11 \pm 0.09^{*}$ & $2.44 \pm 0.13^{@}$ & $2.68 \pm 0.19^{@}$ \\
\hline 3-HS & $2.48 \pm 0.11^{*}$ & $2.91 \pm 0.12 * / @$ & $3.12 \pm 0.09 * / @$ \\
\hline 7-HS & $2.15 \pm 0.14^{*}$ & $2.61 \pm 0.18^{@}$ & $2.89 \pm 0.19 @ / \$$ \\
\hline 12-HS & $1.71 \pm 0.11$ & $2.05 \pm 0.07^{@}$ & $2.31 \pm 0.09 @ / \$$ \\
\hline
\end{tabular}

Table 10. Transversal stiffness $(\mathrm{pN} / \mathrm{nm})$ of isolated gerbil's permeabilized $M G$ muscle fibers in liquid in relaxed, calcium activated $(\mathrm{pCa}=4.2)$ and rigor states under gravitational unloading. * - p<0.05 as compared to the analogous state of the group «Control», ${ }^{\circledR}-p<0.05$ as compared to the relaxed state at the same group, $\$-\mathrm{p}<0.05$ as compared to the activated state at the same group. 


\subsubsection{TA}

The values of transversal stiffness of various parts of the contractile apparatus of fibers of the tibialis anterior muscle of the Mongolian gerbil (Table 11) are practically the same as those of rat (Table 5). The changes appearing during the gravitational unloading, just like for the soleus muscle and the medial gastrocnemius muscle, are not so prominent and are smoothed faster. The increase of stiffness of the contractile apparatus between the Z-disk and the M-band observed after one day of gravitational unloading begins to decrease by the third day, and the value of the parameter in question is the same as the control value 12 days after the suspension begins. Similar differences in the unloading trends are observed at the Z-disk, however, its transversal stiffness differs from the control group only in the relaxed state, while after the activation of contraction and in rigor there are no reliable differences compared to the control values in similar states. The transversal stiffness of the M-band, unlike the area of the semi-sarcomere and Z-disk, increases compared to the control value one day after the gravitational unloading begins, but the differences disappear after three days.

The transversal stiffness of the sarcolemma (Table 12) changes similarly to changes in the stiffness of the contractile apparatus. However, there are no changes in the transversal stiffness of the segment of the membrane between the projections of the Z-disk and the

\begin{tabular}{|c|c|c|c|}
\hline Group $\quad$ State & Relaxed & $\begin{array}{l}\text { Activated } \\
(\mathrm{pCa}=4.2)\end{array}$ & Rigor \\
\hline \multicolumn{4}{|c|}{ Transversal stiffness of the half-sarcomere area $k_{\perp c a}$} \\
\hline Control & $2.56 \pm 0.22$ & $3.90 \pm 0.26^{@}$ & $5.7 \pm 0.3^{@ / \$}$ \\
\hline 1-HS & $4.52 \pm 0.26^{*}$ & $5.50 \pm 0.28 * / @$ & $9.6 \pm 0.5^{* / @ / \$ ~}$ \\
\hline 3-HS & $3.40 \pm 0.21^{*}$ & $5.06 \pm 0.23 * / @$ & $8.1 \pm 0.5^{* / @ / \$ ~}$ \\
\hline 7-HS & $3.26 \pm 0.26^{*}$ & $4.12 \pm 0.14^{@}$ & $7.7 \pm 0.3^{*} / @ / \$$ \\
\hline 12-HS & $2.94 \pm 0.20$ & $4.01 \pm 0.28 @$ & $6.9 \pm 0.5 @ / \$$ \\
\hline \multicolumn{4}{|c|}{ Transversal stiffness of the M-band area $k_{\perp M l}$} \\
\hline Control & $2.8 \pm 0.6$ & $6.4 \pm 0.3^{@}$ & $8.1 \pm 0.5^{\circledR / \$}$ \\
\hline 1-HS & $4.7 \pm 0.4^{*}$ & $8.1 \pm 0.4 * / @$ & $11.9 \pm 0.4^{* / @ / \$}$ \\
\hline 3-HS & $3.3 \pm 0.4$ & $7.78 \pm 0.29 @$ & $9.6 \pm 0.5^{@ / \$}$ \\
\hline 7-HS & $3.1 \pm 0.3$ & $7.32 \pm 0.25^{@}$ & $8.5 \pm 0.5^{@ / \$}$ \\
\hline 12-HS & $2.8 \pm 0.3$ & $6.70 \pm 0.20^{@}$ & $8.4 \pm 0.6^{@ / \$}$ \\
\hline \multicolumn{4}{|c|}{ Transversal stiffness of the Z-disk area $k_{\perp Z d}$} \\
\hline Control & $5.9 \pm 0.3$ & $8.3 \pm 0.9^{@}$ & $12.6 \pm 0.5^{@ / \$}$ \\
\hline 1-HS & $8.3 \pm 0.5^{*}$ & $10.9 \pm 0.5^{* / @ ~}$ & $14.6 \pm 0.8^{* / @ / \$}$ \\
\hline 3-HS & $7.9 \pm 0.4^{*}$ & $9.8 \pm 0.5^{@}$ & $13.8 \pm 0.8^{@ / \$}$ \\
\hline 7-HS & $7.6 \pm 0.3^{*}$ & $9.2 \pm 0.5^{@}$ & $12.6 \pm 0.7^{\circledR / \$}$ \\
\hline 12-HS & $7.1 \pm 0.4^{*}$ & $8.6 \pm 0.4^{@}$ & $12.9 \pm 0.9 @ / \$$ \\
\hline
\end{tabular}

Table 11. Transversal stiffness $(\mathrm{pN} / \mathrm{nm})$ of isolated gerbil's Triton-treated TA muscle fibers in liquid in relaxed, calcium activated $(\mathrm{pCa}=4.2)$ and rigor states under gravitational unloading. * - p<0.05 as compared to the analogous state of the group «Control», ${ }^{-}$p $<0.05$ as compared to the relaxed state at the same group, $\$-p<0.05$ as compared to the activated state at the same group. 


\begin{tabular}{|c|c|c|c|}
\hline Group State & Relaxed & $\begin{array}{l}\text { Activated } \\
(\mathrm{pCa}=4.2)\end{array}$ & Rigor \\
\hline \multicolumn{4}{|c|}{ Transversal stiffness of sarcolemma between the M-band and Z-disk projections $k_{\perp s}$} \\
\hline Control & $2.51 \pm 0.08$ & $2.32 \pm 0.09$ & $2.68 \pm 0.17$ \\
\hline 1-HS & $2.11 \pm 0.12^{*}$ & $1.94 \pm 0.11^{*}$ & $2.06 \pm 0.17^{*}$ \\
\hline 3-HS & $2.01 \pm 0.13^{*}$ & $1.72 \pm 0.19^{*}$ & $1.45 \pm 0.27^{*}$ \\
\hline 7-HS & $2.15 \pm 0.19$ & $1.76 \pm 0.23$ & $1.81 \pm 0.26$ \\
\hline 12-HS & $2.18 \pm 0.12$ & $1.94 \pm 0.11$ & $2.01 \pm 0.18$ \\
\hline \multicolumn{4}{|c|}{ Transversal stiffness of sarcolemma at the M-band projection $k_{\perp M l s}$} \\
\hline Control & $1.61 \pm 0.17$ & $2.45 \pm 0.11^{@}$ & $2.63 \pm 0.22^{\circledR}$ \\
\hline 1-HS & $2.11 \pm 0.08^{*}$ & $2.62 \pm 0.17 @$ & $2.92 \pm 0.19 @$ \\
\hline 3-HS & $1.83 \pm 0.06$ & $2.75 \pm 0.19^{@}$ & $3.04 \pm 0.23^{@ / \$}$ \\
\hline 7-HS & $1.93 \pm 0.18$ & $2.95 \pm 0.19^{@}$ & $3.12 \pm 0.22 @ / \$$ \\
\hline 12-HS & $1.56 \pm 0.09$ & $2.37 \pm 0.11^{@}$ & $2.51 \pm 0.13^{@}$ \\
\hline \multicolumn{4}{|c|}{ Transversal stiffness of sarcolemma at the Z-disk projection $k_{\perp Z d s}$} \\
\hline Control & $2.65 \pm 0.07$ & $3.12 \pm 0.13^{@}$ & $3.64 \pm 0.12^{@ / \$}$ \\
\hline 1-HS & $3.05 \pm 0.12^{*}$ & $3.46 \pm 0.17^{* / @ ~}$ & $3.65 \pm 0.13^{@}$ \\
\hline 3-HS & $3.22 \pm 0.08^{*}$ & $3.54 \pm 0.09 * / @$ & $3.81 \pm 0.14^{@}$ \\
\hline 7-HS & $3.35 \pm 0.13^{*}$ & $3.66 \pm 0.14^{* / @ ~}$ & $3.98 \pm 0.15^{@ / \$}$ \\
\hline 12-HS & $2.74 \pm 0.08$ & $3.01 \pm 0.13^{@}$ & $3.27 \pm 0.11^{@ / \$}$ \\
\hline
\end{tabular}

Table 12. Transversal stiffness ( $\mathrm{pN} / \mathrm{nm}$ ) of isolated gerbil's permeabilized TA muscle fibers in liquid in relaxed, calcium activated $(\mathrm{pCa}=4.2)$ and rigor states under gravitational unloading. * - p $<0.05$ as compared to the analogous state of the group «Control», $@-p<0.05$ as compared to the relaxed state at the same group, $\$-p<0.05$ as compared to the activated state at the same group.

M-band when the contraction is activated both in the control group and during the gravitational unloading. At the same time, the transversal stiffness of the membrane in the projection of the Z-disk and the M-band increases when the contraction is activated and, in some cases, even in rigor, compared to the activated state. The changes of transversal stiffness at various areas of the sarcolemma in the course of gravitational unloading are uneven. Thus, the stiffness in the area between the Z-disk and the M-band decreases after one and three days since the start of gravitational unloading; at the M-band projection it increases after one day and only in the relaxed state; at the Z-disk projection the transversal stiffness is increased relative to the control level after one day of suspension and up to the seventh day of suspension.

\subsection{The transversal stiffness of the rat's left ventricular cardiomyocytes}

In the control group (Table 13), the transversal stiffness of the contractile apparatus of fibers of the left ventricle of rat near the semi-sarcomere, i.e. between the Z-disk and the M-band increased in the sequence relaxation-activation-rigor. This value increased reliably from relaxation to activation. This situation did not change after one day of antiorthostatic suspension. However, in three days, the stiffness of the contractile apparatus reliably increased near the semi-sarcomere both in the relaxed and in the activated/rigor states 
compared to similar states in the control group. This increase was even more prominent seven days after antiorthostatic suspension. Nevertheless, during the antiorthostatic suspension and during activation of contraction, the stiffness of the semi-sarcomere reliably decreased compared to the relaxed state.

\begin{tabular}{|c|c|c|c|}
\hline Group State & Relaxed & $\begin{array}{l}\text { Activated } \\
(\mathrm{pCa}=4.2)\end{array}$ & Rigor \\
\hline \multicolumn{4}{|c|}{ Transversal stiffness of the half-sarcomere area $k_{\perp c a}$} \\
\hline Control & $7.1 \pm 0.4$ & $11.0 \pm 0.5^{@}$ & $13.2 \pm 0.5^{@}$ \\
\hline 1-HS & $6.8 \pm 0.3$ & $10.3 \pm 0.3^{@}$ & $12.9 \pm 0.3^{@}$ \\
\hline 3-HS & $8.2 \pm 0.3^{*}$ & $13.8 \pm 0.4^{*} / @$ & $14.7 \pm 0.3^{*} / @$ \\
\hline 7-HS & $8.9 \pm 0.3^{*}$ & $13.5 \pm 0.3^{*} / @$ & $15.3 \pm 0.3^{*} / @$ \\
\hline 14-HS & $8.7 \pm 0.4^{*}$ & $13.6 \pm 0.4^{*} / @$ & $15.6 \pm 0.4^{*} / @$ \\
\hline \multicolumn{4}{|c|}{ Transversal stiffness of the M-band area $k_{\perp M l}$} \\
\hline Control & $9.9 \pm 0.6$ & $15.0 \pm 0.6^{@}$ & $16.4 \pm 0.5^{@}$ \\
\hline 1-HS & $8.9 \pm 0.5$ & $14.1 \pm 0.4^{@}$ & $15.8 \pm 0.5^{@}$ \\
\hline 3-HS & $9.3 \pm 0.5$ & $14.8 \pm 0.6^{@}$ & $16.3 \pm 0.5^{@}$ \\
\hline 7-HS & $10.6 \pm 0.4$ & $14.9 \pm 0.5^{@}$ & $16.5 \pm 0.8^{@}$ \\
\hline 14-HS & $9.8 \pm 0.5$ & $14.2 \pm 0.6^{\circledR}$ & $15.7 \pm 0.3^{\circledR}$ \\
\hline \multicolumn{4}{|c|}{ Transversal stiffness of the Z-disk area $k_{\perp Z d}$} \\
\hline Control & $16.0 \pm 1.3$ & $22.5 \pm 1.5^{@}$ & $24.5 \pm 0.9^{@}$ \\
\hline 1-HS & $15.4 \pm 0.6$ & $21.6 \pm 0.3^{\circledR}$ & $24.8 \pm 0.6^{@}$ \\
\hline 3-HS & $15.9 \pm 0.6$ & $23.4 \pm 0.7^{@}$ & $26.1 \pm 1.3^{\circledR}$ \\
\hline 7-HS & $15.9 \pm 0.5$ & $21.7 \pm 0.3^{@}$ & $25.9 \pm 0.6^{@}$ \\
\hline 14-HS & $15.8 \pm 0.8$ & $21.9 \pm 0.9^{@}$ & $22.9 \pm 0.7^{@}$ \\
\hline
\end{tabular}

Table 13. Transversal stiffness $(\mathrm{pN} / \mathrm{nm})$ of isolated rat's Triton-treated left ventricular myocytes in liquid in relaxed, calcium activated $(\mathrm{pCa}=4.2)$ and rigor states under gravitational unloading. ${ }^{*}-\mathrm{p}<0.05$ as compared to the analogous state of the group «Control», @ - p $<0.05$ as compared to the relaxed state at the same group, $\$-p<0.05$ as compared to the activated state at the same group.

At the M-band, the stiffness of the contractile apparatus of fibers of the left ventricular of rat was higher than the stiffness of the semi-sarcomere. During the anti-orthostatic suspension, the transversal stiffness of the M-band did not change. The transversal stiffness of the Z-disk is significantly higher than in the semi-sarcomere and the M-band. It also, just like described above, increased during activation and rigor. The trends of changes in the transversal stiffness of the Z-disk were similar to those for the M-band. The transversal stiffness of various segments of glycerinated fibers of the left ventricular of rat (Table 14) in the control group increased during the activation of contraction and in rigor compared to the relaxed state.

After one day of antiorthostatic suspension, the transversal stiffness of the sarcolemma between the Z-disk and M-band projections in the relaxed state reliably increased relative to the control values, but did not differ from the control values in the activated and rigor states. After three days of suspension, the transversal stiffness of the sarcolemma increased even more and continued to increase up to the 14th day, and it reliably differed from the control value in the relaxed, activated and rigor states. Moreover, after 14 days of 
suspension, the transversal stiffness values of this area during activation and in rigor did not reliably differ from the values in the relaxed state. The transversal stiffness of the sarcolemma in the M-band projection in the relaxed state reliably increased compared to the control levels by the 3rd day of suspension and subsequently increased up to the 14th day. The transversal stiffness values in this area in the activated and rigor states did not differ from the control level. The transversal stiffness of sarcolemma in the Z-disk projection reliably increased only by the 14 th day of suspension.

\begin{tabular}{|c|c|c|c|}
\hline Group State & Relaxed & $\begin{array}{l}\text { Activated } \\
(\mathrm{pCa}=4.2)\end{array}$ & Rigor \\
\hline \multicolumn{4}{|c|}{ Transversal stiffness of sarcolemma between the M-band and Z-disk projections $k_{\perp s}$} \\
\hline Control & $4.03 \pm 0.11$ & $9.1 \pm 0.4^{@}$ & $9.67 \pm 0.24^{@}$ \\
\hline 1-HS & $4.80 \pm 0.22^{*}$ & $9.5 \pm 0.5^{@}$ & $10.1 \pm 0.3^{@}$ \\
\hline 3-HS & $6.22 \pm 0.29^{*}$ & $10.2 \pm 0.3^{*} / @$ & $10.8 \pm 0.4^{*} / @$ \\
\hline 7-HS & $7.79 \pm 0.12^{*}$ & $10.5 \pm 0.3^{*} / @$ & $13.3 \pm 0.4^{*} / @$ \\
\hline 14-HS & $12.3 \pm 0.4^{*}$ & $12.9 \pm 0.4^{*}$ & $13.3 \pm 0.3^{*} / @$ \\
\hline \multicolumn{4}{|c|}{ Transversal stiffness of sarcolemma at the M-band projection $k_{\perp M l s}$} \\
\hline Control & $2.85 \pm 0.12$ & $6.8 \pm 0.5^{@}$ & $7.4 \pm 0.6^{\circledR}$ \\
\hline 1-HS & $2.68 \pm 0.17$ & $6.6 \pm 0.3^{@}$ & $7.0 \pm 0.3^{\circledR}$ \\
\hline $3-\mathrm{HS}$ & $3.77 \pm 0.25^{*}$ & $6.7 \pm 0.4^{@}$ & $7.7 \pm 0.5^{@}$ \\
\hline 7-HS & $5.79 \pm 0.19 *$ & $6.9 \pm 0.3^{@}$ & $7.9 \pm 0.3^{@}$ \\
\hline 14-HS & $7.55 \pm 0.13^{*}$ & $7.9 \pm 0.6^{*}$ & $9.4 \pm 0.3^{*} / @$ \\
\hline \multicolumn{4}{|c|}{ Transversal stiffness of sarcolemma at the Z-disk projection $k_{\perp Z d s}$} \\
\hline Control & $10.0 \pm 0.3$ & $14.5 \pm 1.2^{@}$ & $15.3 \pm 0.5 @$ \\
\hline 1-HS & $10.7 \pm 0.8$ & $15.4 \pm 0.3^{\circledR}$ & $16.3 \pm 0.5^{@}$ \\
\hline 3-HS & $10.6 \pm 0.3$ & $14.8 \pm 0.3^{\circledR}$ & $15.2 \pm 0.7^{@}$ \\
\hline 7-HS & $10.4 \pm 0.3$ & $11.9 \pm 0.3^{\circledR}$ & $16.5 \pm 0.3^{\circledR}$ \\
\hline 14-HS & $17.2 \pm 0.4^{*}$ & $17.9 \pm 0.4^{*}$ & $18.2 \pm 0.5^{*} / @$ \\
\hline
\end{tabular}

Table 14. Transversal stiffness $(\mathrm{pN} / \mathrm{nm})$ of isolated rat's permeabilized left ventricular myocytes in liquid in relaxed, calcium activated $(\mathrm{pCa}=4.2)$ and rigor states under gravitational unloading. ${ }^{*}-\mathrm{p}<0.05$ as compared to the analogous state of the group «Control», @ - p<0.05 as compared to the relaxed state at the same group, $\$-p<0.05$ as compared to the activated state at the same group.

\section{Discussion}

The obtained experimental data shows that during simulate microgravity, the stiffness of various parts of muscle fiber in various skeletal muscles, and the cardiac muscle varies in different ways. The results of changes of transversal stiffness of various skeletal muscles of rat were discussed earlier (Ogneva, 2010). Thus, the stiffness of the contractile apparatus of the relaxed soleus muscle of rat does not change relative to the control value on the first day of gravitational unloading. By the 3rd day, the stiffness of the Z-disk of relaxed fiber significantly decreases, reaching its lowest level, and remains the same for the rest of the suspension period. As we showed earlier, after one day of gravitational unloading, the fibers of the soleus muscle of rat and Mongolian gerbil increase the basal content of calcium 
ions (Ogneva et al., 2009). This may lead to activation of calcium-dependent proteases, the calpains (Enns et al., 2007). The structure of the Z-disk includes a number of proteins that are substrates of calpains (Sanger \& Sanger, 2008). It is their destruction that may lead to early reduction of stiffness of the Z-disk as observed in the experiments. At the same time, the changes of stiffness of the Z-disk in the activated state are not so prominent: the decrease is smoother, although the difference in stiffness between the activated and rigor condition significantly decreases. The stiffness values of the M-band and the semi-sarcomere slowly decrease starting from the end of the 3rd day and reach their minimum level only by the 12th day. In the activated state, though, these changes of the M-band and the semisarcomere develop much faster. This effect may be due to several reasons. First of all, titin and nebulin, the proteins of the contractile apparatus, are also substrates of calpains, and their destruction is observed by the seventh day of functional unloading (Goto et al., 2003; Kasper \& Xun, 2000; Shenkman et al., 2004). Second of all, the decrease of the basal number of closed bridges may also lead to a decrease in the transversal stiffness of the contractile apparatus both in the relaxed and in the activated state. The reduction of the basal number of bridges is also evidenced by various data about the reduction of the calcium sensitivity of muscle fibers, which also reflects the number of closed transversal bridges during the gravitational unloading. Thus, by the seventh day of hypokinesia, a decrease of pCa0 (McDonald \& Fitts, 1995) is observed, reflecting the concentration of calcium at which the muscle fiber starts significantly contracting, being initiated by a certain number of closed transversal bridges. By the way, it may also cause reduction of stiffness in the activated state, because pCa50 also decreases during the gravitational unloading (McDonald \& Fitts, 1995). The possibility of closing of transversal bridges is affected by a number of factors, including the efficiency of transfer of tension in the longitudinal direction, requiring coordination of closing of bridges in adjacent sarcomeres, mobility of myosin heads, and inter-filament distance (lattice spacing). The first of these factors may be reduced due to calcium-dependent degradation of titin (see above) and destruction of the Z-disk. The mobility of myosin heads is more likely to increase as a result of the increase in the phosphorilation of light myosin chains (Stewart et al., 2009), which is helped by the increase of the general level of activity of phosphokinase in the course of the gravitational unloading (Barton, 2006). Moreover, the increase of the basal concentration of calcium also helps the increase of the possibility of formation of transversal bridges, although the calcium sensitivity of "quick" isoforms of myosin is lower, and the reliable slow-to-fast shift is observed as early as by the seventh day of the unloading (Booth \& Kelso, 1973; Caiozzo et al. 1996; Desplanches et al. 1990). The effect of changes of the lattice spacing on the transversal stiffness was shown by Xu et al. (1993) and Ranatunga et al. (1990), in experiments with osmotic agents. But the question is whether the lattice spacing is changed during the gravitational unloading. We can only suppose that the destruction of the Z-disk and M-band may cause an increase of the lattice spacing. This suggestion is confirmed by the fact that other changes develop somewhat later, namely by the 7th day of unloading, while the decrease of the stiffness of the Z-disk and contractile apparatus is observed by the 3rd day of hypokinesia.

At the same time, reliable decrease of the transversal stiffness of the sarcolemma is observed as early as by the first day of gravitational unloading. Similarly to the results of Costa et al. (2006) obtained using human aortic cells, it can be suggested that such changes are related to the destruction of the sub-membrane actin cytoskeleton, which is consistent with the data of 
Collinsworth et al. (2002). This destruction may be related either to the destruction of actin fillaments or dissociation of actin-binding proteins, particularly the alpha-actinin-1, alphaactinin-4, filamin, and Arp-proteins. A change of actin content under gravitational unloading was observed on non-muscle cells (Infanger et al., 2007; Rijken et al., 1992), which may confirm the destruction of cortical cytoskeleton, and this may be the reason for the reduction of transversal stiffness of the sarcolemma. Changes near the costamere are observed in rats after one day of unloading, but by the 12th day of suspension, this value restores. The reduction of costamere stiffness may be related to its destruction as a result of loss of desmin, the key protein of costamere enabling the transfer of tension from the contractile apparatus to the sarcolemma (Capetanaki et al., 2007; Ervasti, 2003). Desmin is a substrate of a specific calcium-dependent proteolysis system, the calpain system. Enns et al. (2007) demonstrated that desmin content in the mixture of the soleus and gastrocnemius muscle significantly decreases by the third day and is almost completely restored by the ninth day. Chopard et al. (2005) demonstrated that in case of long-term antiorthostatic suspension of rats, desmin content in the fibers of the soleus muscle is not changed. The experimental data obtained by us earlier show that the desmin content in fibers of the soleus muscle reduces one day after the suspension, reliably decreases after three days and reaches the minimum after seven days; in twelve days, the desmin content in the soleus muscle is not different from the control value (Ogneva, 2010).

The situation is different when studying the fibers of the medial gastrocnemius muscle and the tibialis anterior muscle. By the first day of gravitational unloading, the stiffness of the contractile apparatus of relaxed fibers of these muscles reliably increases, and it does so much more in the area of the semi-sarcomere than at the Z-disk. Then, in the course of unloading, the stiffness of the contractile apparatus of fibers of the gastrocnemius muscle returns to the control level, while in fibers of the tibialis anterior muscle it remains above the original values. Basing on the explanations of changes in the stiffness of the contractile apparatus of the soleus muscle, it can be assumed that during the first day of gravitational unloading, either the mobility of myosin heads increases, or the lattice spacing decreases. The changes are implemented in the area of semi-sarcomere, since the changes of stiffness of the Z-disk and the M-band are not so prominent. The change of the lattice spacing in this case might only be caused by a change in physical and chemical factors that remained constant during the experiment. This is why we may suggest that the increase of the stiffness of fibers of the gastrocnemius muscle and tibialis anterior muscle is caused by an increase of mobility of myosin heads due to possible increase of the general phosphorylation level in the cells observed during the gravitational unloading (Barton, 2006).

The transversal stiffness of the sarcolemma of fibers of both muscles, just like those of the soleus muscle reliably decreases by the first day of gravitational unloading, which, similarly to fibers of the soleus muscle, may be related to the destruction of the cortical cytoskeleton. Nevertheless, after seven days of unloading, the transversal stiffness of the sarcolemma of fibers of the gastrocnemius muscle increases and reaches the control values, while that of fibers of the tibialis anterior muscle even somewhat exceeds the control level. The stiffness of the costamere of fibers of the gastrocnemius muscle and the tibialis anterior muscle somewhat increases after three and seven days of suspension, but returns to the original values by the 12th day, which suggests another trend of changes of desmin content compared to the soleus muscle. Desmin content in fibers of the gastrocnemius muscle remains almost unchanged during the gravitational unloading, and is only slightly 
increased by the seventh day of suspension, while in the tibialis anterior muscle it reliably increases by the first day of gravitational unloading, peaks on the third day, and then somewhat decreases, but remains reliably higher than the control level (Ogneva, 2010).

Changes in the stiffness of fibers of the Mongolian gerbil during the gravitational unloading are similar to those of the rat, although they are less prominent and either occur later or the changes are smoothed out earlier. Our previous data (Ogneva et al., 2009) confirm a significantly higher original intra-cell ionized calcium content in rats compared to gerbils; as early as 1 day after the gravitational unloading begins, both animals show an increase of calcium content by 2.8 and 4.5 times respectively in fibers of the soleus muscle. It is possible that the originally lower calcium ion content in the muscle fiber of gerbils compared to rats, and possibly higher osmolarity of their interstitial environment confirm that they have a higher electrochemical gradient for calcium ions on the membrane of the muscle fiber in the normal state, which, for example, may mean another level of activation of the calpain system. Desmin content in slow and fast muscles in the control group correspond to the same parameters in rats (our unpublished data). Nevertheless, it should be noted that stiffness of the sarcolemma, costamere and costamere-like structure of fibers of all studied muscles, especially the soleus muscle, is higher in Mongolian gerbils than in rats.

At the same time, changes of the transversal stiffness of cardiac myocytes were opposite. Some knowledge has accumulated that confirms changes of the contractile activity and conductivity of the myocard in space flight of humans and animals (Bungo et al., 1985; Goldstein et al., 1992). At the same time, the structural and functional basis of such changes, mainly implemented on the cell level, has almost not been studied (Xiong et al., 2003). The data we obtained confirms that as a result of simulated microgravity, the transversal stiffness of the contractile apparatus of cardiac myocytes in the area of transversal bridges is increased similarly to the contractile apparatus of fibers of the tibialis anterior muscle. At the same time, transversal stiffness of the sarcolemma of cardiac myocytes considerably increases at the earliest stages of simulated microgravity.

By comparing the results obtained with fibers of skeletal muscles and cardiac myocytes using atomic force microscopy, we may propose the following suggestions about the reaction of muscle fibers to changes of external mechanical conditions. The decrease of nervous activation, like in Sol (Alford et al., 1987) causes a decrease of stiffness of the contractile apparatus of fibers of skeletal muscles, possible due to changes in the efficiency of transfer of tension in the longitudinal direction due to changes in the lattice spacing. An increase of activity, like in TA (Alford et al., 1987), and increase of the load, like in the cardiac muscle, may lead to the prevalence of factors increasing the mobility of myosin heads. Moreover, there is a direct proportional dependence between the level of activation and content of desmin as a protein ensuring transfer of tension from the contractile apparatus to the sarcolemma.

The level of activity does not affect the studied structural and functional properties of the sarcolemma. Apparently, the direct decrease of load as a mechanical factor affecting any cell may cause a decrease of stiffness of the cell membrane, as it occurs in the tibialis anterior muscle under the conditions of antiorthostatic suspension. The increase of load under these conditions, which is typical for the cardiac muscle, causes an increase of the transversal stiffness of cardiac myocytes. The mechanism of change of the transversal stiffness of the cell membrane (reduction if the load reduces and increase if the load increases) is apparently 
related to restructuring of the cortical cytoskeleton. This may, for example, modulate the activity of membrane channels, signal paths connected with membrane proteins and be of key importance in launching processes ensuring mechanical sensitivity of cells, possibly not only those of muscles.

\section{Acknowledgment}

The authors express gratitude to all employees of myology laboratory of SSC RF - IBMP RAS. The work was supported by the program of the fundamental research SSC RF - IBMP RAS as well as by RFBR grant 10-04-00106-a.

\section{References}

Akiyama, N.; Ohnuki, Y.; Kunioka, Y.; Saeki, Y. \& Yamada, T. (2006). Transverse stiffness of myofibrils of skeletal and cardiac muscles studied by atomic force microscopy. Journal of physiological sciences, Vol.56, pp. 145-151.

Alford, E.K.; Roy, R.R.; Hodgson, J.A. \& Edgerton, V.R. (1987). Electromyography of rat soleus, medial gastrocnemius and tibialis anterior during hind limb suspension. Experimental neurology, Vol.96, pp. 635-649.

Altaeva, E.G.; Lysenko, L.A.; Kantserova, N.P.; Nemova, N.N. \& Shenkman, B.S. (2010). The basal calcium level in fibers of the rat soleus muscle under gravitational unloading: the mechanisms of its increase and the role in calpain activation. Doklady biological sciences : proceedings of the Academy of Sciences of the USSR, Biological sciences sections / translated from Russian, Vol.433, pp. 241-243.

Barton, E.R. (2006) Impact of sarcoglycan complex on mechanical signal transduction in murine skeletal muscle. American journal of physiology. Cell physiology, Vol.290, pp. 411-419.

Bloch, R.J. \& Gonzalez-Serratos, H. (2003). Lateral force transmission across costameres in skeletal muscle. Exercise and sport sciences reviews, Vol.31, pp. 73-78.

Booth, F.W. \& Kelso J.R. (1973). Effect of hind-limb immobilization on contractile and histochemical properties of skeletal muscle. Pflügers Archiv : European journal of physiology, Vol.342, pp. 231-238.

Bungo, M.W.; Charles, J.B. \& Jonson P.C. Jr. (1985). Cardiovascular deconditioning during space flight and the use of saline as a countermeasure to orthostatic intolerance. Aviation, space, and environmental medicine, Vol.56, No. 10, pp. 985-990.

Caiozzo, V.J.; Haddad, F.; Baker, M.J.; Herrick, R.E.; Prietto, N. \& Baldwin K.M. (1996). Microgravity-induced transformations of myosin isoforms and contractile properties of skeletal muscle. Journal of applied physiology, Vol.81, pp. 123-132.

Capetanaki, Y.; Bloch, R.J.; Kouloumenta, A.; Mavroidis, M. \& Psarras, S. Muscle intermediate filaments and their links to membranes and membranous organells. Experimental cell research, Vol.313, pp. 2063-2076.

Chopard, A.; Arrighi, N.; Carnino, A. \& Marini, J.F. (2005). Changes in dysferlin, proteins from dystrophin glycoprotein complex, costameres, and cytoskeleton in human soleus and vastus lateralis muscles after a long-term bedrest with or without exercise. The FASEB journal : official publication of the Federation of American Societies for Experimental Biology, Vol.19, pp. 1722-1724. 
Collinsworth, A.M.; Zhang, S.; Kraus, W.E. \& Truskey G.A. (2002). Apparent elastic modulus and hysteresis of skeletal muscle cells throughout differentiation. American journal of physiology. Cell physiology, Vol.283, pp. 1219-1227.

Costa, K.D.; Sim, A.J. \& Yin F.C. (2006). Non-Hertzian approach to analyzing mechanical properties of endothelial cells probed by atomic force microscopy. Journal of biomechanical engineering, Vol.128, pp. 176-184.

Defranchi, E.; Bonaccurso, E.; Tedesco, M.; Canato, M.; Pavan, E.; Raiteri, R. \& Reggiani, C. (2005). Imaging and elasticity measurements of the sarcolemma of fully differentiated skeletal muscle fibres. Microscopy research and technique, Vol.67, pp. 27-35.

Desplanches, D.; Mayet, M.H.; Ilyina-Kakueva, E.I.; Sempore, B. \& Flandrois, R. Skeletal muscle adaptation in rats flown on Cosmos 1667. Journal of applied physiology, Vol.68, pp. 48-52.

Enns, D.L.; Raastad, T.; Ugelstad, I.; Belcastro, A.N. (2007). Calpain/calpastatin activities and substrate depletion patterns during hindlimb unweighting and reweighting in skeletal muscle. European journal of applied physiology, Vol.100, pp. 445-455.

Ervasti, J.M. (2003). Costameres: the Achilles' Heel of Herculean muscle. Journal of biological chemistry, Vol.278, pp. 13591-13594.

Goldstein, M.A.; Edwards, R.J. \& Schroeter, J.P. (1992). Cardiac morphology after conditions of microgravity during COSMOS 2044. Journal of applied physiology, Vol.73, 2 Suppl, pp. $94 \mathrm{~S}-100 \mathrm{~S}$.

Goto, K.; Okuyama, R.; Honda, M.; Uchida, H.; Akema, T.; Ohira, Y. \& Yoshioka, T. (2003). Profiles of connectin (titin) in atrophied soleus muscle induced by unloading of rats. Journal of applied physiology, Vol.94, pp. 897-902.

Hertz, H. (1882). Ueber die Beruhrung fester alastischer Korper. Reine Angew Mathematik, Vol.92, pp. 156-171.

Infanger, M.; Ulbrich, C.; Baatout, S.; Wehland, M.; Kreutz, R.; Bauer, J.; Grosse, J.; Vadrucci, S.; Cogoli, A.; Derradji, H.; Neefs, M.; Kusters, S.; Spain, M.; Paul, M. \& Grimm, D. Modeled gravitational unloading induced downregulation of endothelin-1 in human endothelial cells. Journal of cellular biochemistry, Vol.101, pp. 1439-1455.

Ingalls, C.P.; Warren, G.L. \& Armstrong, R.B. (1999). Intracellular Ca2+ transients in mouse soleus muscle after hindlimb unloading. Journal of applied physiology, Vol.87, pp. 386-390.

Ingalls, C.P.; Wenke, J.C. \& Armstrong, R.B. (2001). Time course changes in [Ca2+]i, force and protein content in hindlimb-suspended mouse soleus muscles. Aviation, space, and environmental medicine, Vol.72, pp. 471- 476.

Kasper, C.E. \& Xun, L. (2000). Expression of titin in skeletal muscle varies with hind-limb unloading. Biological research for nursing, Vol.2, pp. 107-115.

Lieber et, S.C.; Aurby, N.; Pain, J.; Diaz, G.; Kim, S.J. \& Vatner, S.F. (2004). Aging increases stiffness of cardiac myocytes measured by atomic force microscopy nanoindentation. American journal of physiology. Heart and circulatory physiology, Vol.287, No.2, pp. H645-H651.

Mathur, A.B.; Collinsworth, A.M.; Reichert, W.M.; Kraus, W.E. \& Truskey, G.A. (2001). Endothelial, cardiac muscle and skeletal muscle exhibit different viscous and elastic properties as determined by atomic force microscopy. Journal of biomechanics, Vol.34, pp. 1545-1553. 
McDonald, K.S. \& Fitts, R.H. (1995). Effect of hindlimb unloading on rat soleus fiber force, stiffness, and calcium sensitivity. Journal of applied physiology, Vol.79, pp. 1796-1802.

Morey-Holton, E.; Globus, R.K.; Kaplansky, A. \& Durnova, G. (2005). The hindlimb unloading rat model: literature overview, technique update and comparison with space flight data. Advances in space biology and medicine, Vol.10, pp. 7-40.

Nyland, L.R. \& Maughan, D.W. (2000). Morphology and transverse stiffness of Drosophila myofibrils measured by atomic force microscopy. Biophysical journal, Vol.78, pp. 1490-1497.

Ogneva, I.V.; Kurushin, V.A.; Altaeva, E.G.; Ponomareva, E.V. \& Shenkman, B.S. (2009). Effect of short-time gravitational unloading on rat and Mongolian gerbil muscles. Journal of muscle research and cell motility, Vol.30, pp. 261-265.

Ogneva, I.V.; Lebedev, D.V. \& Shenkman, B.S. (2010). Transversal stiffness and Young's modulus of single fibers from rat soleus muscle probed by atomic force microscopy. Biophysical journal, Vol.98, pp. 418-424.

Ogneva, I.V. (2010). The transversal stiffness of fibers and the desmin content in the leg muscles of rats under gravitational unloading of various duration. Journal of applied physiology, Vol.109, pp. 1702-1709.

Radmacher, M.; Fritz, M.; Kacher, C.M.; Cleveland, J.P. \& Hansma, P.K. (1996). Measuring the viscoelastic properties of human platelets with atomic force microscope. Biophysical journal, Vol.70, No.1, pp. 556-557.

Ranatunga, K.W.; Fortune, N.S. \& Geeves, M.A. (1990). Hydrostatic compression in glycerinated rabbit muscle fibers. Biophysical journal, Vol.58, pp. 1401-1410.

Rijken, P.J.; de Groot R.P.; Kruijer, W.; de Laat, S.W.; Verkleij, A.J. \& Boonstra, J. (1992). Identification of specific gravity sensitive signal transduction pathways in human A431 carcinoma cells. Advances in space research: the official journal of the Committee on Space Research (COSPAR), Vol.12, pp. 145-152.

Robinson, P.F. (1959). Metabolism of the Gerbil, Meriones Unguiculatus. Science, Vol.130, pp. 502-503.

Sanger, J.M. \& Sanger, J.W. (2008). The dynamic Z band of striated muscle cells. Science signaling [electronic resource], Vol.1, pp. 37-39.

Shenkman, B.S.; Litvinova, K.S.; Nemirovskaya, T.L.; Podlubnaya, Z.A.; Vikhlyantsev, I.M. \& Kozlovskaya, I.B. (2004). Afferent and peripheral control of muscle fiber properties during gravitational unloading. Journal of gravitational physiology : a journal of the International Society for Gravitational Physiology, Vol.11, pp. 111-114.

Shin, D. \& Athanasiou, K. (1999). Cytoindentation for obtaining cell biomechanical properties. Journal of orthopaedic research : official publication of the Orthopaedic Research Society, Vol.17, No.6, pp. 880-890.

Sneddon, I.N. (1965). The relation between load and penetration in the axisymmetric boussinesq problem for a punch of arbitrary profile. International journal of engineering science, Vol.3, pp. 47-57.

Stevens, L.; Holy, X. \& Mounier, Y. (1993). Functional adaptation of different rat skeletal muscles to weightlessness. American journal of physiology, Vol.264, pp. 770-776.

Stewart, M.; Franks-Skiba, K. \& Cooke, R. (2009). Myosin regulatory light chain phosphorylation inhibits shortening velocities of skeletal muscle fibers in the presence of the myosin inhibitor blebbistatin. Journal of muscle research and cell motility, Vol.30, pp. 17-27. 
Weisenhorn, A.L.; Khorsandi, M.; Kasas, S.; Gotzos, V. \& Butt, H.J. (1993). Deformation and height anomaly of soft surfaces studied with an AFM. Nanotechnology, Vol.4, pp. 106-113.

Xiong, J.; Li, Y. \& Nie, J. (2003). Effects of simulated microgravity on nitric oxide level in cardiac myocytes and its mechanism. Science in China. Series C, Life sciences / Chinese Academy of Sciences, Vol. 46. № 3. pp 302-309.

$\mathrm{Xu}, \mathrm{S}$.; Brenner, B. \& Yu, L.C. (1993). State-dependent radial elasticity of attached crossbridges in single skinned fibres of rabbit psoas muscle. Journal of physiology, Vol.465, pp. 749-765.

Zhu, J.; Sabharwal, T.; Kalyanasundaram, A.; Guo, L. \& Wang, G. (2009). Topographic mapping and compression elasticity analysis of skinned cardiac muscle fibers in vitro with atomic force microscopy and nanoindentation. Journal of biomechanics, Vol.42, No.13, pp. 2143-2150. 


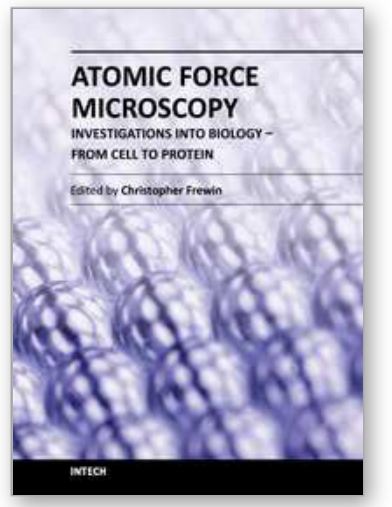

\author{
Atomic Force Microscopy Investigations into Biology - From Cell \\ to Protein \\ Edited by Dr. Christopher Frewin
}

ISBN 978-953-51-0114-7

Hard cover, 354 pages

Publisher InTech

Published online 07, March, 2012

Published in print edition March, 2012

The atomic force microscope (AFM) has become one of the leading nanoscale measurement techniques for materials science since its creation in the 1980 's, but has been gaining popularity in a seemingly unrelated field of science: biology. The AFM naturally lends itself to investigating the topological surfaces of biological objects, from whole cells to protein particulates, and can also be used to determine physical properties such as Young's modulus, stiffness, molecular bond strength, surface friction, and many more. One of the most important reasons for the rise of biological AFM is that you can measure materials within a physiologically relevant environment (i.e. liquids). This book is a collection of works beginning with an introduction to the AFM along with techniques and methods of sample preparation. Then the book displays current research covering subjects ranging from nano-particulates, proteins, DNA, viruses, cellular structures, and the characterization of living cells.

\title{
How to reference
}

In order to correctly reference this scholarly work, feel free to copy and paste the following:

Irina V. Ogneva and Igor B. Ushakov (2012). The Transversal Stiffness of Skeletal Muscle Fibers and Cardiomyocytes in Control and After Simulated Microgravity, Atomic Force Microscopy Investigations into Biology - From Cell to Protein, Dr. Christopher Frewin (Ed.), ISBN: 978-953-51-0114-7, InTech, Available from: http://www.intechopen.com/books/atomic-force-microscopy-investigations-into-biology-from-cell-to-protein/thetransversal-stiffness-of-skeletal-muscle-fibers-and-cardiomyocytes-in-control-and-after-simulate

\section{INTECH}

open science | open minds

\section{InTech Europe}

University Campus STeP Ri

Slavka Krautzeka 83/A

51000 Rijeka, Croatia

Phone: +385 (51) 770447

Fax: +385 (51) 686166

www.intechopen.com

\section{InTech China}

Unit 405, Office Block, Hotel Equatorial Shanghai

No.65, Yan An Road (West), Shanghai, 200040, China

中国上海市延安西路65号上海国际贵都大饭店办公楼 405 单元

Phone: +86-21-62489820

Fax: $+86-21-62489821$ 
(C) 2012 The Author(s). Licensee IntechOpen. This is an open access article distributed under the terms of the Creative Commons Attribution 3.0 License, which permits unrestricted use, distribution, and reproduction in any medium, provided the original work is properly cited. 